\title{
A liver-specific factor essential for albumin transcription differs between differentiated and dedifferentiated rat hepatoma cells
}

\author{
Silvia Cereghini, Marta Blumenfeld, and Moshe Yaniv ${ }^{1}$ \\ Unité des virus oncogènes-UA 041149 de CNRS, Département de biologie moléculaire, Institut Pasteur, 75724 Paris Cedex
} 15 France

\begin{abstract}
We have identified and characterized two mutually exclusive nuclear proteins that interact with a single crucial element of the albumin promoter. One, albumin proximal factor (APF), is found only in liver or differentiated hepatoma cells and is probably identical to the liver-specific factors named HNF1, $\alpha 1$ TFB, or HP1-binding protein. The other, variant albumin proximal factor (VAPF), is present in dedifferentiated hepatoma cells as well as in somatic cell hybrids that show extinction of the expression of liver-specific proteins, including albumin. Reversion to the hepatic phenotype of either a dedifferentiated variant or an extinguished somatic hybrid clone is accompanied by loss of VAPF and reappearance of APF. These two proteins differ in their thermostability and in their molecular weight, while displaying identical sequence specificities. Both proteins interact with a homologous motif present in promoter regions of several other liver-specific genes. In vitro transcription assays, using a rat liver nuclear extract, indicate that the binding of APF to its target sequence is required for albumin transcription. These results suggest that a modification in the primary structure of a transcription factor is correlated with the differentiated state of the hepatic cell.
\end{abstract}

[Key Words: Tissue-specific gene expression; transcriptional factors; hepatocyte differentiation]

Received March 24, 1988; revised version accepted June 22, 1988.

The albumin gene is subject to developmental and tissue-specific regulation. This gene is expressed mainly in liver cells, where early in fetal development it is coactivated along with the closely linked and evolutionarily related $\alpha$-fetoprotein (AFP) gene. After birth, AFP expression ceases rapidly, whereas albumin synthesis increases to become the major serum protein synthesized and secreted by adult hepatocytes (Panduro et al. 1987, see references therein).

Our interest has been to elucidate the molecular mechanisms involved in the establishment of tissuespecific expression of the albumin gene. Our early studies indicated that the first $150 \mathrm{bp}$ of the rat albumin 5 '-flanking region contain the sequences necessary and sufficient for tissue or cell specificity in a transient expression assay (Ott et al. 1984; Heard et al. 1987). Deletion analysis followed by a more refined study using a series of clustered point mutants identified five distinct transcriptional control elements within these sequences, in addition to the TATA box (Heard et al. 1987; P. Herbomel, A. Rollier, F. Tronche, H.O. OH, M. Yaniv, and M.C. Weiss, in prep.). Figure 1 is a schematic diagram of the minimal albumin promoter illustrating these elements, which are designated as the proximal el-

${ }^{1}$ Corresponding author. ement (PE), the CCAAT box, and the distal elements I, II, and III (DEI, DEII, and DEIII, respectively). Multiple base substitutions in each of these elements affect to different degrees the transcriptional activity of the albumin promoter in vivo; the proximal element and the CCAAT box are the most crucial (P. Herbomel et al., in prep.).

Each one of these elements contains a sequence motif highly conserved among the albumin genes of mice, rats, and humans (Heard et al. 1987) which functions as the recognition site for distinct factors present in liver or differentiated hepatoma cells producing albumin (Babiss et al. 1987; Cereghini et al. 1987; Lichtsteiner et al. 1987; Raymondjean et al. 1988; see Fig. 1A). The factor binding to the DEII site is closely related or identical to nuclear factor 1 or the CCAAT-binding transcription factor (NF1/CTF) purified from HeLa cells (Jones et al. 1985, 1987), whereas the factor binding to the DEI element is the CCAAT/enhancer-binding protein (C/EBP) that was purified from rat liver by Graves et al. (1986; see Fig. 1A) (Johnson et al. 1987; S. Cereghini and P. Johnson, unpubl.).

Interestingly neither of these two well-characterized CCAAT-binding proteins, NF1/CTF and C/EBP, interacts with the albumin CCAAT motif at position -80. Instead we have identified, by a combination of footprint, 


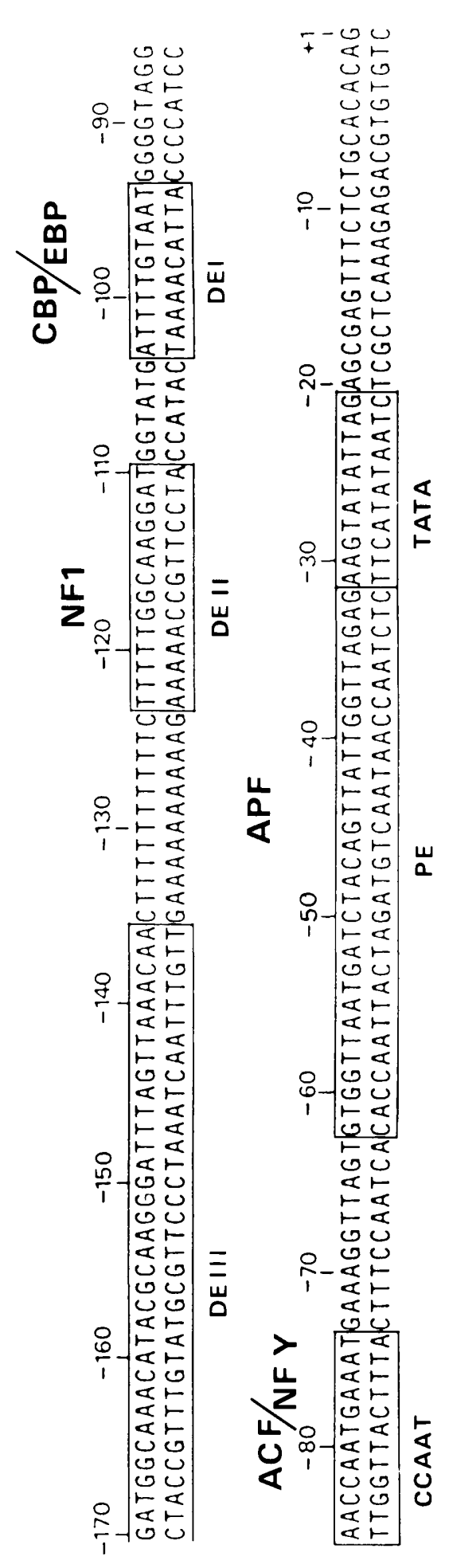

$\infty$

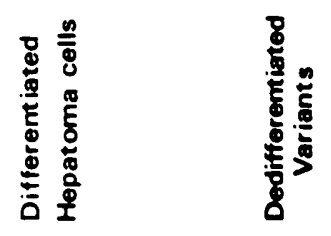

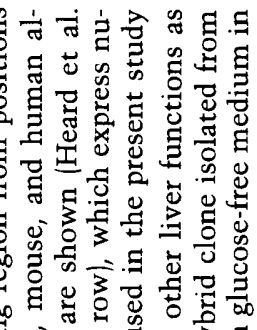

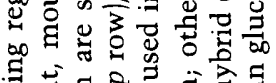

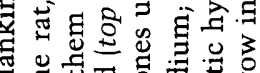

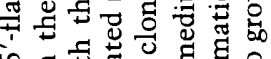

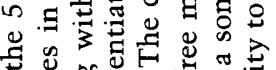

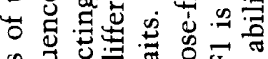

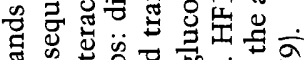

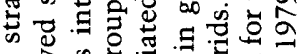

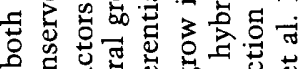

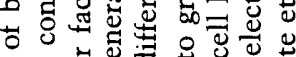
\&

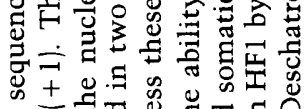

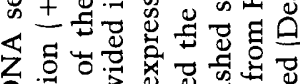

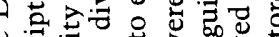

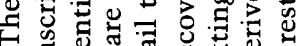

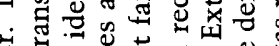

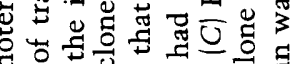
0 过

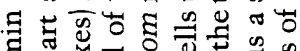
घ $\begin{aligned} & \pi \\ & 0\end{aligned}$ 手舟焉。

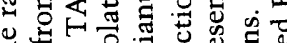
Ð

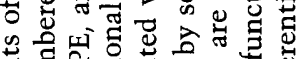

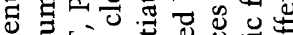

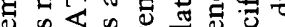
Q

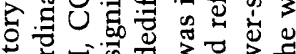

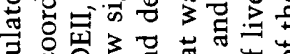

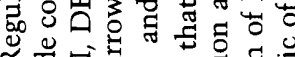

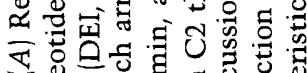

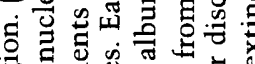
क人

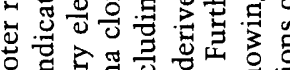

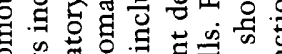

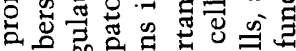

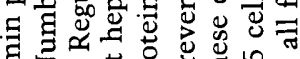

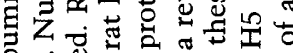
न ह่

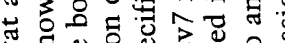
क के

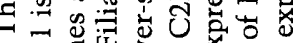

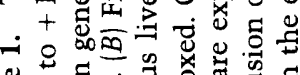

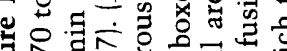

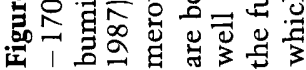


gel retardation, methylation interference, and crosscompetition experiments, a distinct CCAAT-binding factor, termed ACF (albumin CCAAT factor) (Raymondjean et al. 1988). This factor may be identical to the NFY factor that binds to promoters of class II surface antigens (Dorn et al. 1987; M. Raymondjean and A. Dorn, unpubl.). None of these three factors binding to either the CCAAT box or to the DEI and DEII elements seems to be strictly cell-type specific, as judged both by the generation of identical DNase I protection patterns and retarded DNA-protein complexes with these sequence elements when comparing extracts from different cell types. In contrast, a clear difference has been observed in the footprinting patterns on the proximal promoter element with nuclear extracts derived from cells expressing or not expressing the albumin gene, suggesting that these sequences might be recognized by tissue-specific protein(s) (Cereghini et al. 1987). This prompted us to characterize the PE-binding region in detail by using the more sensitive gel mobility shift technique with synthetic oligonucleotides. We have searched for factors in a variety of cell types and focused our attention on a family of rat hepatoma clones representing various stages of hepatocyte differentiation.

This approach has led to the identification of a liverspecific protein, albumin proximal factor $(A P F)$, which interacts with a $15-\mathrm{bp}$, partially palindromic sequence in the center of the albumin proximal element. APF also interacts with a homologous motif present in promoter regions crucial for the in vivo expression of several other liver-specific genes, suggesting that APF acts as a positive trans-acting factor. In vitro transcription experiments using a set of mutant APF-binding sites confirmed that binding of APF is also required for albuminspecific transcription. This protein is absent in nonhepatic cells while a modified form, variant albumin proximal factor (vAPF), was found in two independent lines of dedifferentiated hepatoma cells, $\mathrm{H} 5$ and $\mathrm{C} 2$, and in an 'extinguished' somatic hybrid formed by fusion of differentiated and dedifferentiated cells. Reversion to the hepatic phenotype of either C2 cells or the somatic hybrid clone is accompanied by the reappearance of APF and disappearance of vAPF. Thus, APF is clearly associated with the hepatic phenotype and VAPF with both the dedifferentiated pattern and the extinction event.

\section{Results}

The albumin proximal region interacts with a liverspecific factor

Previous studies indicated that the proximal element is the only region of the albumin promoter that is not identically protected from DNase I digestion by proteins present in expressing and nonexpressing cells suggesting that this element may be recognized by cell-type-specific proteins (Cereghini et al. 1987).

In the present study, we used the electrophoretic mobility shift assay (Fried and Crothers 1981; Garner and Revzin 1981) to screen sequences within the albumin proximal region able to interact specifically with pro- teins present in nuclear extracts from different cell types. Because the proximal region protected by rat liver nuclear proteins $(-35$ to -72$)$ represents slightly more than three helical turns, this site could be recognized by more than a single factor. Therefore, we first synthesized three partially overlapping double-stranded (ds) oligonucleotides (PE12, PE34, PE56; Table 1), encompassing the entire proximal region, and used them either as probes or as cold competitors in the binding assays. Alternatively, these same ds oligonucleotides were used as competitors in DNase I footprinting experiments. Only one out of the three ds oligonucleotides examined (PE56; Table 1) was able to both compete efficiently for the binding of rat liver factor(s) to the entire proximal region in a footprinting assay (not shown) and to form a specific DNA-protein complex (see below). The PE56 oligonucleotide was then used as a probe in the binding assays to examine nuclear extracts from a variety of cell lines of hepatic or nonhepatic origin. The filiation of the rat hepatoma clones relevant to the present work is shown in Figure 1B. As shown in Figure 2A, PE56 formed a unique DNA-protein complex, designated as $\mathrm{Cl}$, when incubated with rat liver or H4II nuclear extracts. A complex with identical electrophoretic mobility was formed using nuclear extracts from the rat hepatoma cell line Fao, the human hepatoma cell line HepG2, and the mouse hepatoma cell line BW1J, all of which are characterized by the expression of the endogenous albumin gene (Fig. 2A and data not shown). In contrast, dedifferentiated rat hepatoma cells ( $\mathrm{H} 5$ and $\mathrm{C} 2)$ that fail to express most of the liver-specific functions, including albumin synthesis, gave rise to a distinct and weaker complex $(\mathrm{C} 2)$ that migrates slightly faster than $\mathrm{C} 1$. Interestingly, C2Rev7, a revertant cell line derived from $\mathrm{C} 2$ that reexpresses albumin and other liver-specific proteins, showed the disappearance of the parental $\mathrm{C} 2$ complex and the reappearance of the hepatic-type $\mathrm{C} 1$ complex. Most instructive is the analysis of the PE56 binding activity in a somatic hybrid, HF1, between Fao and $\mathrm{H} 5$ that causes extinction of the expression of the set of tissue-specific functions that characterizes the differentiated parent (Deschatrette et al. 1979). As shown in Figure $2 \mathrm{~A}$, in HF1 only the $\mathrm{C} 2$ faster-migrating complex is observed. In contrast, HF1-5, a revertant of HF1 hybrids reexpressing albumin and other liver-specific proteins, contained only the hepatic $\mathrm{Cl}$ complex.

Neither the $\mathrm{C} 1$ nor the $\mathrm{C} 2$ species were detected in nonhepatic cells, including mouse ascites, 3T6 mouse fibroblasts, 3T3 transformed rat fibroblasts, the human $\mathrm{T}$ leukemia cells (Jurkat and Iarc cell lines), and HeLa cells. Additional species with mobilities faster than either $\mathrm{Cl}$ or $\mathrm{C} 2$ which resulted from nonspecific interaction of proteins with the PE56 oligonucleotide were noted with some nuclear extracts from these nonhepatic cells (not shown). Analyses of more than 15 different cell lines indicated that complex $\mathrm{Cl}$ is exclusively formed with nuclear extracts derived from hepatic cells, whereas complex $\mathrm{C} 2$ appears to be characteristic of both the dedifferentiated state and the hepatic extinction phenotype. 
Table 1. Oligonucleotides

\begin{tabular}{|c|c|}
\hline PE12 & $\begin{array}{l}-80 \text { ATGAAATGAAAGGTTAGTGTGGTTAATGAT } \\
\text { ACTTTACTTTCCAATCACACCAATTACTAGAT-48 }\end{array}$ \\
\hline PE34 & $\begin{array}{l}-50 \text { CTACAGTTATTGGTTAGAGAAGTATAT } \\
\text { GTCAATAACCAATCTCTTCATATAA -23 }\end{array}$ \\
\hline PE27 mer & $\begin{array}{l}\text { TCGACTGTGGTTAATGATCTACAGTTA } \\
\text { GACACCAATTACTAGATGTCAATAGCT }\end{array}$ \\
\hline PE56 & $\begin{array}{l}-63 \text { TGTGGTTAATGATCTACAGTTA } \\
\text { CACCAATTACTAGATGTCAATA-41 }\end{array}$ \\
\hline Alb CCAAT & $\begin{array}{l}\text {-93 GGGGTAGGAACCAATGAAATGAAAGGTTA } \\
\text { CCCCATCCTTGGTTACTTTACTTTCCAAT-65 }\end{array}$ \\
\hline Alb DE II & $\begin{array}{l}-126 \text { TTCTTTTTGGCAAGGATGGTATGATT } \\
\text { AAGAAAAACCGT TCCTACCATACTAA-101 }\end{array}$ \\
\hline Alb DE I & $\begin{array}{l}-109 \text { GGTATGATTTTGTAATGGGGTAGG } \\
\text { CCATACTAAAACATTACCCCATCC-86 }\end{array}$ \\
\hline NF1 & $\begin{array}{l}20 \text { TATTTTGGATTGAAGCCAATATGATAATGA } \\
\text { ATAAAACCTAACTTCGGTTATACTATTACT } 49\end{array}$ \\
\hline SV40 enhancer core & $\begin{array}{l}233 \text { TGCTGGGGACT T TCCACACCCTAA } 254 \\
\text { ACGACCCCTGAAAGGTGTGGGATT }\end{array}$ \\
\hline Alb Xenopus 68 kd & $\begin{array}{l}\text { 69 ATAGGTTAATAATTTTCCAGAT } \\
\text { ATCCAATTATTAAAAGGTCTAG }-47\end{array}$ \\
\hline rat $B$ fibrinogen & $\begin{array}{l}\text {-101 CAAACTGTCAAATATTAACTAA } \\
\text { TT TGACAGTTTATAATTGATT T -79 }\end{array}$ \\
\hline rat AFP & $\begin{array}{l}\text {-67 GAAGGTTACTAGTTAACAGGCA } \\
\text { TTCCAATGATCAATTGTCCGTA-45 }\end{array}$ \\
\hline human A1AT & $\begin{array}{l}-76 \text { CCT TGGT TAATATTCACCAGCAG } \\
\text { GAACCAATTATAAGTGGTCGTCG -54 }\end{array}$ \\
\hline
\end{tabular}

These differences were not due to the loss or inactivation of factors that may have occurred during the isolation of nuclei since the presence of ubiquitous factors, such as ACF or NF1, were readily detected in all extracts (Fig. 2B and data not shown). Moreover, mixing experiments indicated that nonhepatic extracts do not contain an activity which inhibits the formation of the typical $\mathrm{Cl}$ hepatic complex. Thus, when extracts from either $\mathrm{H} 4 \mathrm{II}$ and $\mathrm{H} 5$ or Fao and $\mathrm{C} 2$ were mixed and incubated with the PE56 probe both the $\mathrm{C} 1$ and $\mathrm{C} 2$ complexes could be readily observed (data not shown; see also Fig. 5 below). The difference between the differentiated and dedifferentiated pattern ( $\mathrm{C} 1$ versus $\mathrm{C} 2$ complex) was also observed over a wide range of protein concentrations, indicating that the major $\mathrm{Cl}$ complex does not derive from the minor $\mathrm{C} 2$ complex. To exclude that the $\mathrm{C} 2$ faster- migrating complex was generated by selective proteolysis of the protein(s) forming the $\mathrm{Cl}$ complex during the preparation of nuclear extracts from dedifferentiated variants, we performed another series of control experiments. The hepatoma H4II and its dedifferentiated derivative $\mathrm{H} 5$ cells were mixed at two different ratios (H4II : H5 were $1: 2.6$ and $1: 11$, respectively) before the isolation of nuclei and preparation of the respective nuclear extracts. As shown in Figure 2C, both the $\mathrm{Cl}$ and the $\mathrm{C} 2$ complexes were obtained in these mixed extracts, with no indication of selective degradation of the $\mathrm{Cl}$ complex. Thus, the faster-migrating $\mathrm{C} 2$ complex specific for dedifferentiated variants does not appear to be the result of artifactual proteolytic degradation.

The sequence specificity of the $\mathrm{C} 1$ and $\mathrm{C} 2$ complexes was then examined in competition experiments using

Figure 2. Two distinct factors interact with the albumin proximal element. Gel electrophoretic mobility shift assays were carried out as described in Materials and methods, using as DNA probes ds-oligonucleotides containing the PE56 sequence and the albumin CCAAT homology (Table 1). The origin of the nuclear extracts and probes used are indicated above and below the lanes, respectively. (A) The albumin proximal element. Detection of two distinct complexes, $\mathrm{Cl}$ and $\mathrm{C} 2$, in differentiated and dedifferentiated hepatoma cells. Binding reactions contained $3 \mu \mathrm{g}$ of rat liver nuclear protein; 4 and $8 \mu \mathrm{g}$ (lanes 2, 3; 7, 8; 11, 12; 17, 18; respectively) of H4II; Fao; Rev7; and HF1-5 nuclear proteins; 4, 8, and $16 \mu$ (lanes $4-6$, respectively) of H5; 8 and $16 \mu \mathrm{g}$ (lanes 9 and 10 , respectively) of C2, 4, 8, 16 , and $20 \mu \mathrm{g}$ (lanes $13-16$, respectively) of HF1 nuclear extracts. The locations of the $\mathrm{C} 1$ and $\mathrm{C} 2$ complexes are indicated by arrows. (B) The albumin CCAAT binding factor. Binding reactions contained no protein (lane 1), 4, and $8 \mu \mathrm{g}$ of the indicated nuclear extracts (lanes $2-15$ ), and $3 \mu \mathrm{g}$ of rat liver nuclear protein (lane 16). (C) PE-binding activity in nuclear extracts from mixed cells. H4II and H5 cells were mixed at ratios $1: 2.6$ and $1: 11$ before the isolation of nuclei and preparation of the respective nuclear extracts. Binding reactions were performed with $3,10,45$, and $7 \mu \mathrm{g}$ (lanes $1-4$, respectively) of the indicated nuclear extracts. DNA-protein complexes and free DNA were fractionated onto a $5 \%$ polyacrylamide gel. 
Transcriptional factors and hepatocyte differentiation

A

(1)

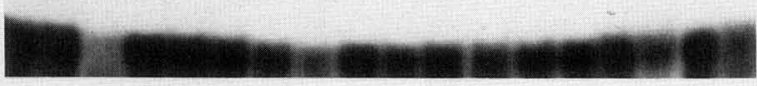

$\begin{array}{llllllllllllllllll}1 & 2 & 3 & 4 & 5 & 6 & 7 & 8 & 9 & 10 & 11 & 12 & 13 & 14 & 15 & 16 & 17 & 18\end{array}$ PE 56

B

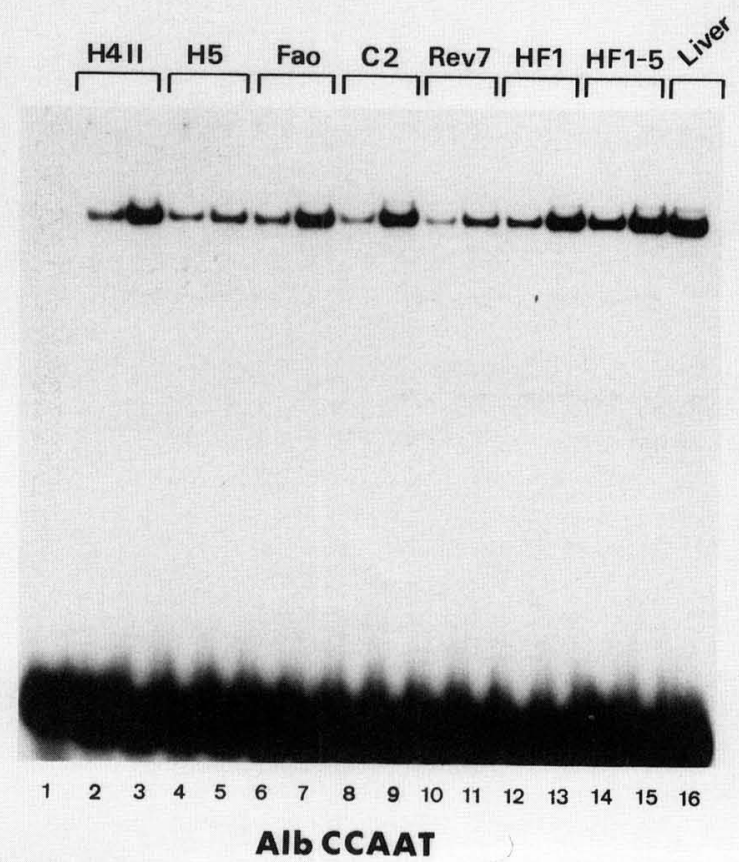

C

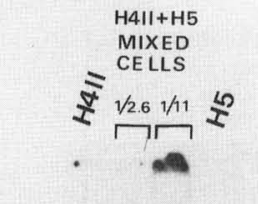

$\mathrm{C1} \rightarrow$ 밴. $-\mathrm{C} 2$

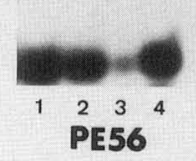

Figure 2. (See facing page for legend). 
specific and nonspecific ds-oligonucleotides as competitors. When the homologous ds-oligonucleotide was used as competitor, the intensity of both the $\mathrm{Cl}$ and $\mathrm{C} 2$ bands was reduced dramatically. Heterologous oligonucleotides containing the SV40 enhancer core sequence, the adenovirus NF1 recognition site, the albumin CCAAT box, or the albumin DEI binding site (Fig. 3B) did not affect the formation of the $\mathrm{Cl}$ and $\mathrm{C} 2$ complexes. Therefore, the proteins comprising complexes $\mathrm{Cl}$ and C2 appeared to have a considerably higher affinity for the PE56 oligonucleotide than for other oligonucleotides containing different recognition sequences.

On the basis of these data as well as the results described below, we have termed the liver-specific PE binding activity as APF (albumin proximal factor) and the $\mathrm{C} 2$ binding activity vAPF (variant APF).

\section{$A P F$ and $V A P F$ make identical contacts on the proximal element}

Methylation interference mapping was performed to de- termine which purine residues are important in the formation of complexes $\mathrm{C} 1$ and $\mathrm{C} 2$. A PE oligonucleotide 27-mer, (Table 1) was partially methylated in vitro with dimethylsulfate (DMS) and used in the binding reactions. DNA fragments in complexes $\mathrm{C} 1$ and $\mathrm{C} 2$ as well as the corresponding unbound fragments were isolated from the preparative native polyacrylamide gel, subjected to a $\mathrm{G}+\mathrm{A}$-specific chemical cleavage, and the products displayed on a sequencing gel (Fig. 4). Methylated $G$ and $A$ residues that interfered with binding of the proteins are depleted from the DNA-protein complex and appear underrepresented in the sequence ladder relative to free DNA.

As indicated by arrows in Figure 4A and summarized in Figure 4B, methylation of $G$ residues at positions -60 and -59 on the upper strand and at positions -50 and -47 on the lower strand interferes with the formation of both $\mathrm{C} 1$ and $\mathrm{C} 2$ complexes. Methylation of other $\mathrm{G}$ residues does not interfere with binding. Methylation of $\mathrm{A}$ -51 on the lower strand partially affected $\mathrm{Cl}$ and $\mathrm{C} 2$ complex formation. Thus, APF and vAPF appear to have indistinguishable DNA binding sites by this assay.
A

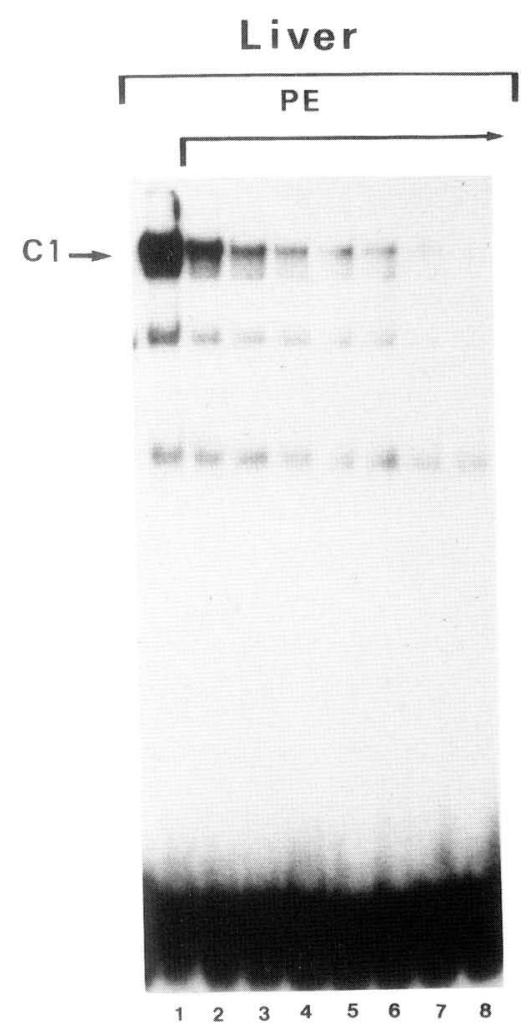

B

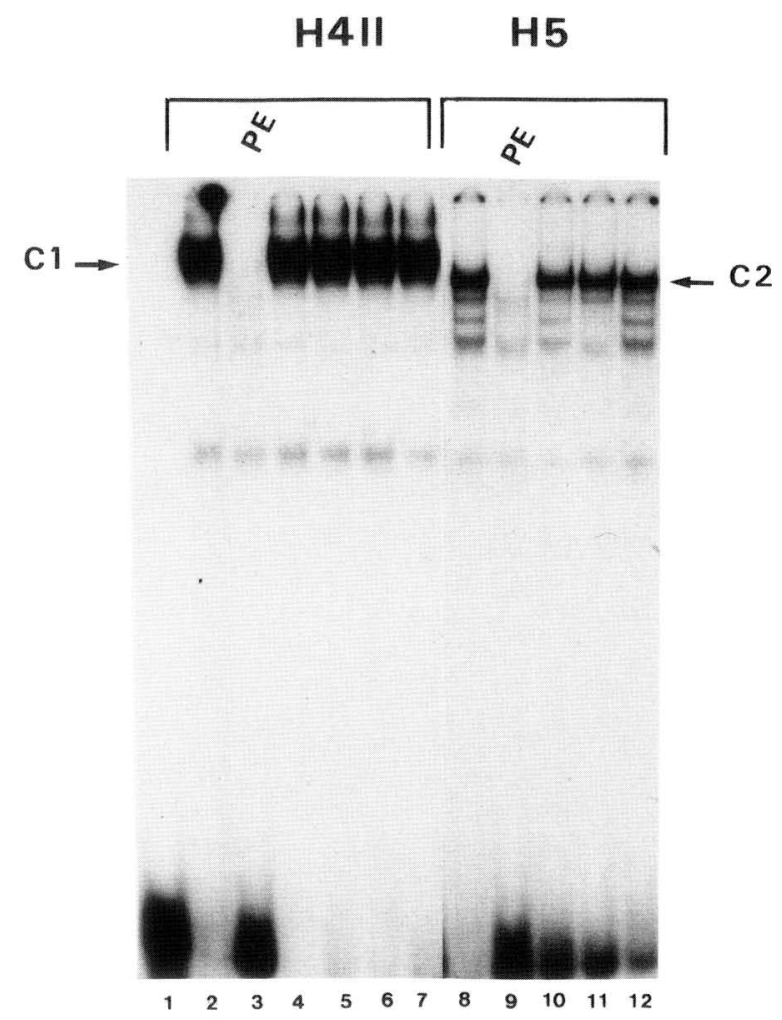

Figure 3. Sequence specificity of the complexes $\mathrm{Cl}$ and $\mathrm{C} 2 .(A)$ Rat liver nuclear extracts. Binding reactions were performed as described in Material and methods except that $50 \mathrm{ng}$ of salmon sperm DNA was used. ${ }^{32}$ P-Labeled $5^{\prime}$ and PE56 oligonucleotide (1 ng) was incubated with $3 \mu \mathrm{g}$ of rat liver nuclear extracts in the absence (lane 1) or in the presence of 1, 2, 3, 5, 10, and 20 ng (lanes $2-7$, respectively) of cold PE56 oligonucleotide. (B) Homologous and heterologous competitions. Seven micrograms of H4II or $12 \mu \mathrm{g}$ of $\mathrm{H} 5$ nuclear extracts were incubated with $0.20 \mathrm{ng}$ of PE56 probe in the absence (lanes 2 and 8 ) or in the presence of $10 \mathrm{ng}$ of PE56 (lanes 3 and 9); $20 \mathrm{ng}$ of DEI (lanes 4 and 10); $20 \mathrm{ng}$ of albumin CCAAT (lanes 5 and 11); $20 \mathrm{ng}$ of SV40 core enhancer (lanes 6 and 12); and 20 ng of NF1 (lane 7) ds oligonucleotides (see Table 1). 
A

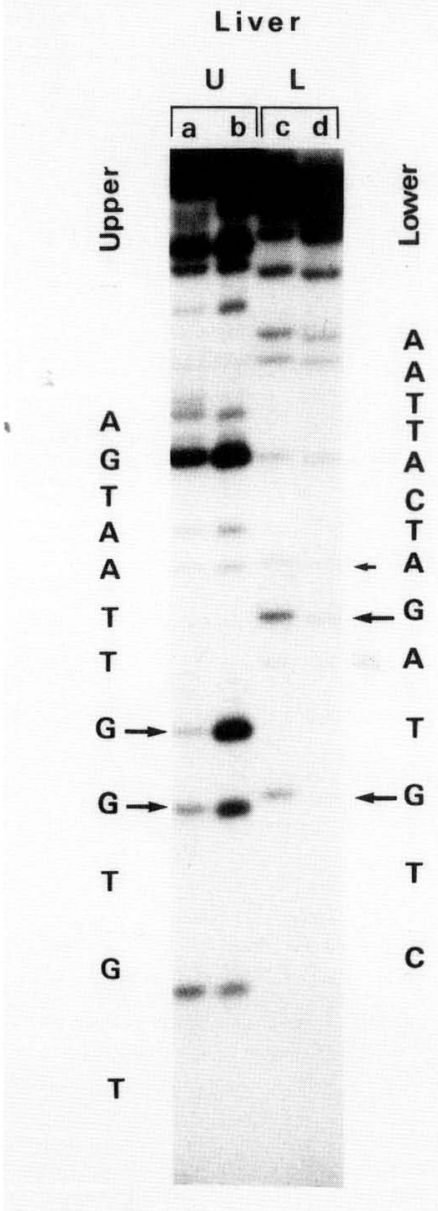

H4 II

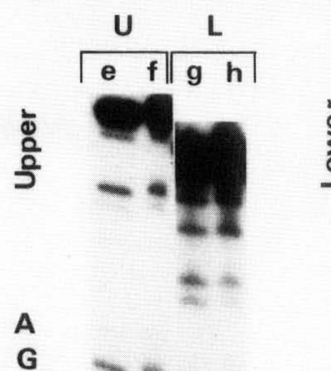

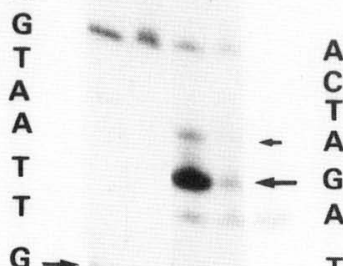

$G \rightarrow$ G

T

G

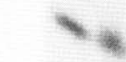

$\mathbf{T}$

G
H5
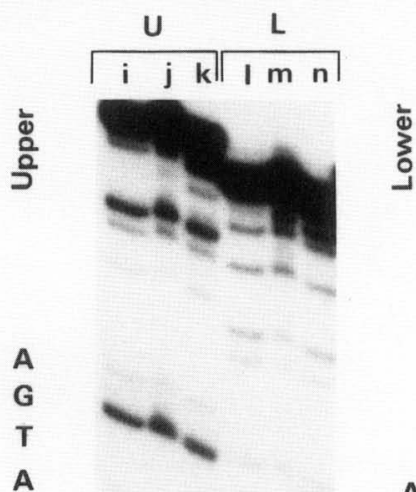

$\begin{array}{ll}\text { A } & \text { A } \\ \text { A } & \text { C }\end{array}$

T T

$T+\mathbf{A}$

G $\rightarrow \downarrow-\quad-G$

G $\rightarrow+$ A

$\mathbf{T}$

G

$\mathbf{T}$
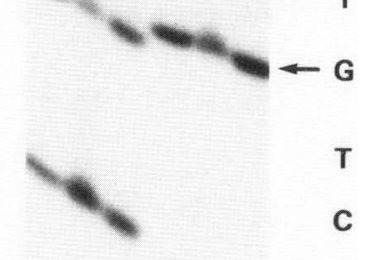

A

A

\begin{tabular}{l} 
A \\
T \\
A \\
G \\
A \\
T \\
G \\
\hline$T$ \\
C
\end{tabular}

A

G

G

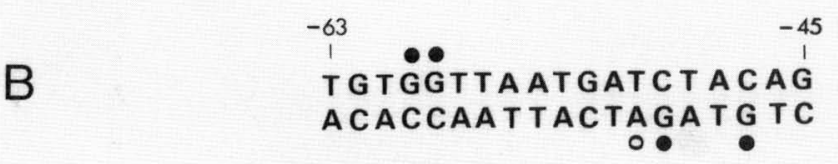

Figure 4. DMS methylation interference analysis. (A) The PE oligonucleotide, PE27-mer, (Table 1), which contains the PE56 sequence plus a XhoI restriction site at both extremities, was $5^{\prime}$-end-labeled, partially methylated, and used as probe in the binding reactions with the indicated nuclear extract as described in Materials and methods. Lanes $b, c, e, g, i, k, 1$ and $n$ correspond to the unbound DNAs; lanes $a, d, f$, and $h$ correspond to the DNA from $\mathrm{Cl}$ complex (liver or H4II); and lanes $j$ and $m$ correspond to the DNA from $\mathrm{C} 2$ complex $(\mathrm{H} 5)$. Long and short arrows indicate strongly and weakly interfering methylated purine residues respectively. (B) Summary of methylation interference analysis. Purine residues strongly $(\bullet)$ and weakly $(0)$ protected by proteins from either liver, $\mathrm{H} 4 \mathrm{II}$, or H5 cells and their location on the PE recognition sequence are indicated.

The proteins forming complexes $C 1$ and $C 2$ are distinct To characterize APF and vAPF further, we have compared various biochemical properties including heat stability, optimal $\mathrm{Mg}^{2+}$ concentration, and polypeptide composition. The relative thermostability was examined by heating for $5 \mathrm{~min}$ at various temperatures undiluted nuclear extracts from H4II, and H5 cells and analyzing their binding activities in a standard gel retardation assay (Fig. 5). Under these conditions the $\mathrm{Cl}$ activity of albumin-positive $\mathrm{H} 4 \mathrm{II}$ cells still persists at $60^{\circ} \mathrm{C}$ and to a lesser extent at $80^{\circ} \mathrm{C}$ whereas the $\mathrm{C} 2$ binding activity of the albumin-negative $\mathrm{H} 5$ cells is completely abolished by heating at these two temperatures. The same inactivation pattern was also observed when $\mathrm{H} 4 \mathrm{II}$ and $\mathrm{H} 5$ or Fao and $\mathrm{C} 2$ extracts were mixed before heating, clearly indicating that the different heat labilities observed are not due to a particular protein composition and/or concentration of the nuclear ex- 
A

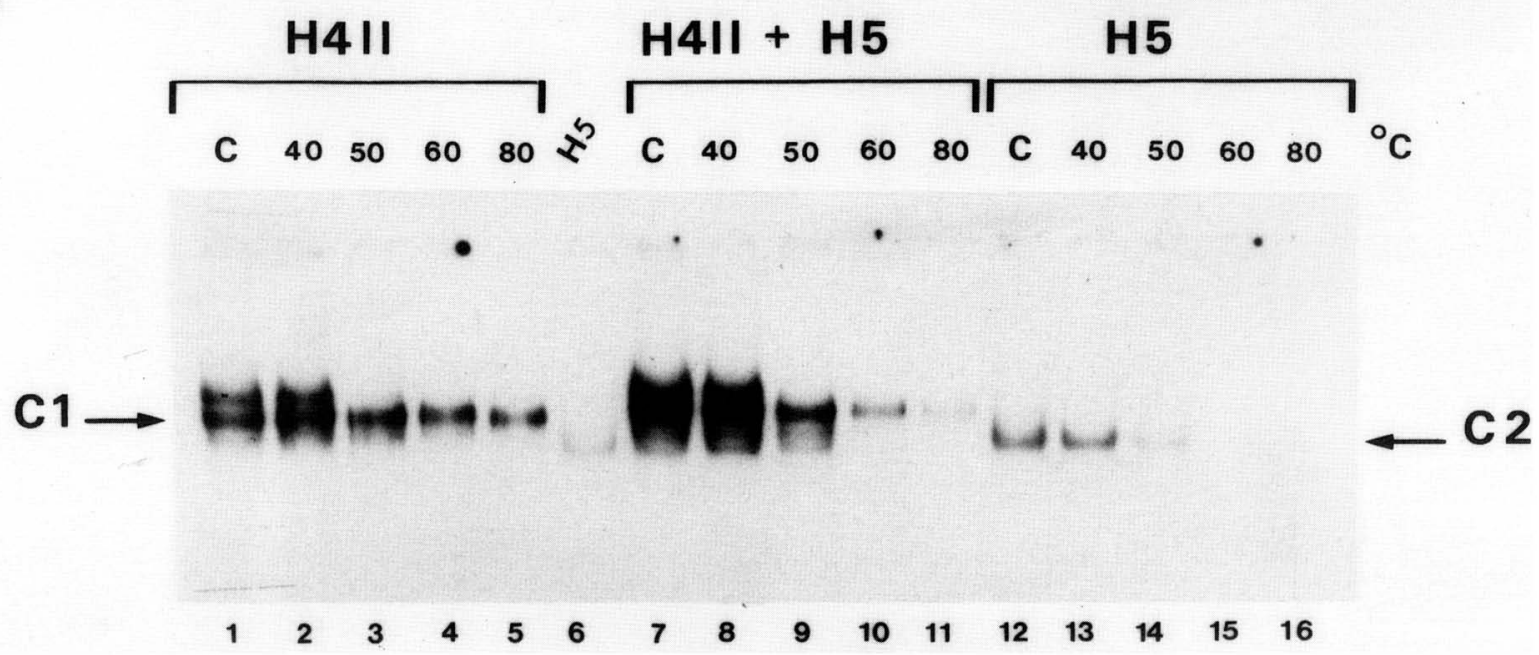

Figure 5. Thermostability of APF and vAPF binding activities. Either $7 \mu \mathrm{g}$ of $\mathrm{H} 4 \mathrm{II}$ (lanes $1-5$ ); $10 \mu \mathrm{g}$ of H5 (lane 6 ); $17.5 \mu \mathrm{g}$ of $\mathrm{H} 5$ (lanes $12-16$ ); or $7 \mu \mathrm{g}$ of H4II $+17.5 \mu \mathrm{g}$ of $\mathrm{H} 5$ (lanes $7-11$ ) nuclear proteins were used in binding reactions. Nuclear extracts were incubated $5 \mathrm{~min}$ at the indicated temperature and cooled on ice, and denatured proteins were removed by centrifugation and assayed for binding activity in the presence of $0.1 \% \mathrm{NP}-40$ and $0.5 \mu \mathrm{g} / \mathrm{ml}$ of serum albumin. DNA-protein complexes and free DNA were loaded onto a $5 \%$ polyacrylamide gel containing $0.25 \times \mathrm{TBE}+1 \mathrm{mM} \mathrm{MgCl}_{2}$ and electrophoresed until a suitable separation of complexes $\mathrm{C} 1$ and $\mathrm{C} 2$ in the mixed extracts was achieved.

tracts (Fig. 5 and data not shown). When mixed extracts were assayed, we performed higher-resolution gel electrophoresis analysis to clearly resolve complex $\mathrm{Cl}$ from complex $\mathrm{C} 2$. These conditions revealed the presence of an additional heat-labile component in all the albuminpositive nuclear extracts (data not shown; see also Fig. 5) that migrated slightly slower than complex $\mathrm{Cl}$. We did not characterize any further this band that may result from the interaction of a heat labile cellular protein with the $\mathrm{Cl}$ complex.

Finally, both $\mathrm{C} 1$ and $\mathrm{C} 2$ binding activities require $\mathrm{Mg}^{2+}$ as a cofactor: no complexes are observed in the absence of this cation and their formation is stimulated when the $\mathrm{Mg}^{2+}$ concentration is increased from $4 \mathrm{mM}$ to $9 \mathrm{~mm}$ (data not shown).

The electrophoretic analysis of DNA-protein complexes provides no information as to the polypeptides involved in complex formation. To identify and compare the polypeptides present in the $\mathrm{Cl}$ and $\mathrm{C} 2$ complexes, a photochemical cross-linking protocol was used to label polypeptides selectively on the basis of their specific binding to the PE oligonucleotide. This technique recently has been applied successfully to the identification of the adenovirus major late transcription factor (MLTF) (Chodosh et al. 1986) and the serum response factor (SRF) polypeptides in HeLa nuclear extracts (Treisman 1987). A DNA probe was prepared by incorporating bromodeoxyuridine (BrdU) and radioactive deoxyadenosine into the noncoding strand (lower strand) of the PE 27 mer oligonucleotide (Table 1). The substitution of thymidine by BrdU did not affect the formation of either $\mathrm{Cl}$ or $\mathrm{C} 2$ complexes as assayed by gel electrophoresis of DNA-protein complexes (data not shown). Nuclear extracts from either rat liver differentiated or dedifferen- tiated cells were incubated with the body-labeled PE oligonucleotide under the standard conditions, and the resulting DNA-protein complexes and the unbound probe were fractionated in a preparative native polyacrylamide gel. The gel was then irradiated with an ultraviolet light lamp (312-nm wavelength), DNA-protein complexes were excised from the gel, and the cross-linked proteins were resolved by electrophoresis on SDS-polyacrylamide gels. This procedure eliminates the cross-linking of nonspecific proteins present in the nuclear extracts by selecting the particular DNA-protein complex for which binding site specificity has been shown unambiguously. As illustrated in Figure 6, UV irradiation resulted in the covalent attachment of the PE oligonucleotide to a single polypeptide in all the albumin-positive extracts examined, while two labeled species of a different size were present in all the albumin-negative extracts. Because the covalent attachment of short oligonucleotides has a minor measurable effect on the mobility of these proteins in SDS-polyacrylamide gel electrophoresis /see Materials and methods), these experiments indicate that a polypeptide of $\sim 100 \mathrm{kD}$ is involved in the liver-specific $\mathrm{Cl}$ complex and two polypeptides, a major one of $82 \mathrm{kD}$ and a minor one of $68 \mathrm{kD}$, are present in the $\mathrm{C} 2$ complex. The degree of photolabeling of these polypeptides $(100 \mathrm{kD}$ and $82-68 \mathrm{kD})$ was a function of the extract concentration and consequently of the intensity of the respective $\mathrm{Cl}$ and $\mathrm{C} 2$ complexes, and was not affected by adding nonspecific oligonucleotides in the binding assays (data not shown; see also Fig. 6). More importantly, when a partially purified fraction from rat liver enriched in $\mathrm{Cl}$ binding activity was used, the same $100-\mathrm{kD}$ polypeptide was photolabeled (see the respective lane in Fig. 6). 


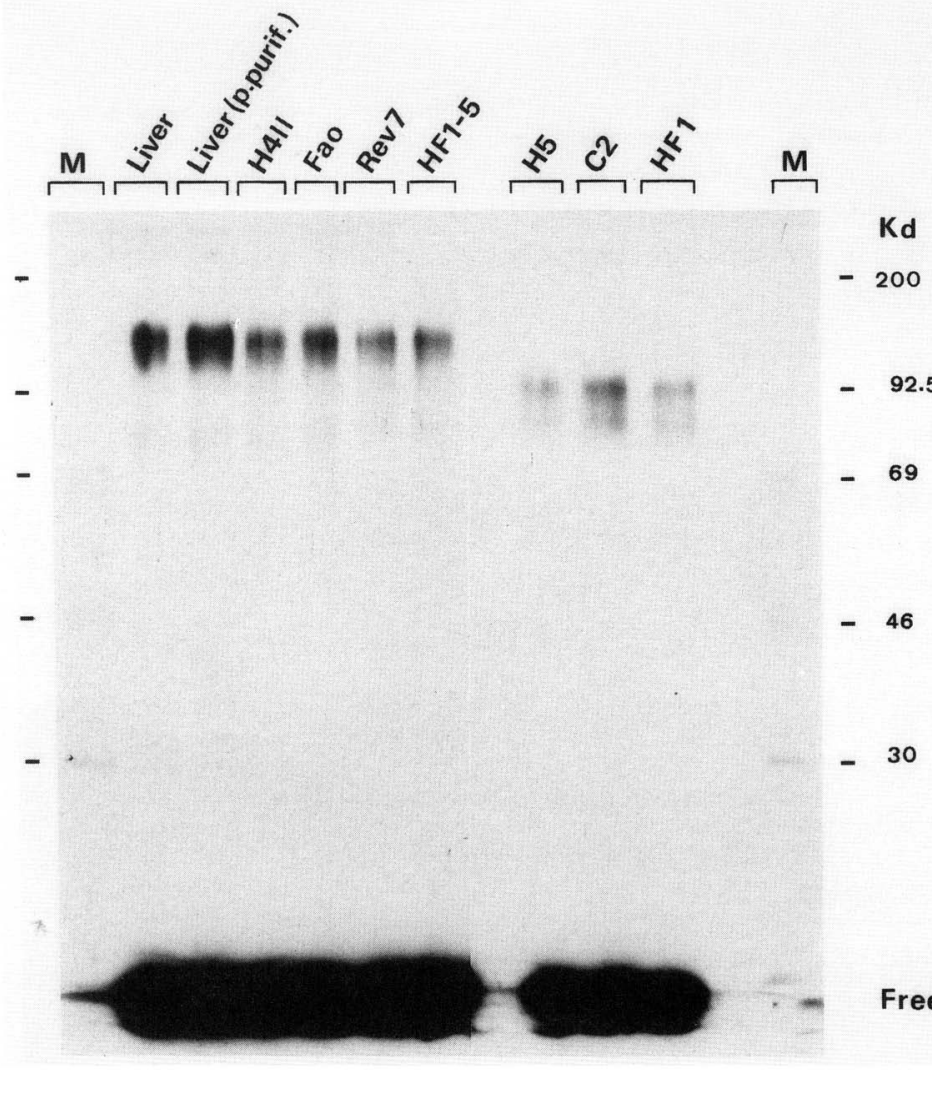

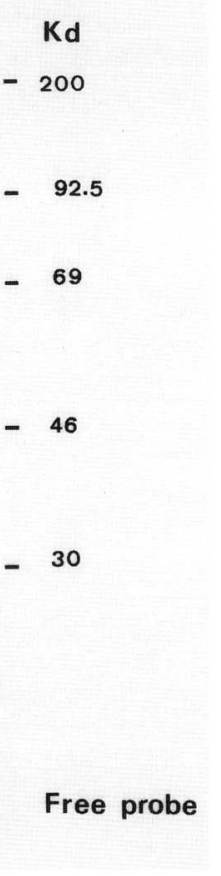

Figure 6. Identification of polypeptides involved in the formation of $\mathrm{C} 1$ and $\mathrm{C} 2$ complexes by photoactivated cross-linking. Binding reactions were carried out as described in Materials and methods except that they were scaled up. From left to right, binding reactions contained $20 \mu \mathrm{g}$ of rat liver nuclear extract; a partially purified fraction (Ultrogel AcA44 chromatography); $60 \mu \mathrm{g}$ of H4II; $56 \mu \mathrm{g}$ of FaO; $70 \mu \mathrm{g}$ of Rev7; $60 \mu \mathrm{g}$ of $\mathrm{HF} 1-5 ; 105 \mu \mathrm{g}$ of $\mathrm{H} 5 ; 100 \mu \mathrm{g}$ of $\mathrm{C} 2$; and $128 \mu \mathrm{g}$ of HF1 nuclear proteins. Molecular weight markers and their positions are indicated at both sides of the autoradiograph.
APF interacts with regulatory regions of other liverspecific genes

The APF binding site contains a partially palindromic sequence $(-60$ GGTTAATGATCTACA - 46) centered on nucleotide -53 (Table 1). A related 15-bp motif is present at similar positions in the promoter sequences of several other liver-specific genes, including frog, chicken, mouse, and human albumin genes; rat, mouse, and human AFP genes; rat $\alpha$-fibrinogen and $\beta$-fibrinogen $(\beta$-Fib) genes; human $\alpha$-1-antitrypsin gene (A1AT); and the rat pyruvate kinase gene. A similar motif is found further upstream in the human haptoglobin gene (Table 2). For some of these promoter sequences (AFP, AlAT, $\beta$-Fib, Xenopus albumin) there is experimental evidence that they are involved in promoter functions in vivo (Godbout et al. 1986; Courtois et al. 1987; DeSimone et al. 1987; Schorpp et al. 1988).

To examine whether these related promoter sequences are recognized by APF we performed two series of experiments. First, we constructed a series of 22-mer oligonucleotides containing the PE56 homologous sequences present within the Xenopus $68-\mathrm{kD}$ albumin, the rat $\mathrm{AFP}$, the rat $\beta$-fibrinogen, and the human $\mathrm{AlAT}$ promoters (Table 1) and tested them in the gel retardation assay.

With all these oligonucleotides we readily observed a retarded complex at the same position as that reflecting the binding of APF to the PE56 oligonucleotide (C1) (data not shown). Except for $\beta$-fibrinogen, in all other cases, the intensity of the retarded band was weaker than that observed with PE56. This suggested that APF can bind to these various related promoter sequences with the following relative affinities: PE56 $=\beta$-fibrinogen $>$ AlAT - AFP $>$ Xen 68. However, because distinct proteins can generate identical shifts in this assay (as an example, see Dorn et al. 1987), we performed a second series of experiments in which we compared the ability of the same unlabeled oligonucleotides to compete for APF binding to the labeled PE56 fragment. The formation of APF-PE56 complex was competed differently by these oligonucleotides (Fig. 7A). Comparison of the amount of oligonucleotide competitor required to achieve 50\% competition reveals that the PE56 and the $\beta$-fibrinogen fragments are the best competitors (Fig. 7A). Most importantly, there is a very good correlation between DNA-proteins affinities measured in competition experiments and the relative binding efficiencies revealed by direct gel retardation assays. This indicates that the Xen-68, AFP, A1AT, and $\beta$-fibrinogen oligonucleotides all bind to the same protein.

\section{Fine specificity of APF and $V A P F$}

By comparing the APF binding sites in the promoter of the different genes listed in Table $2 \mathrm{~A}$, it has been possible to derive a consensus sequence $5^{\prime}{ }_{A}$ GTTA $^{A}{ }_{C}$ $\mathrm{TNNT}^{\mathrm{C}}{ }_{\mathrm{T}} \mathrm{NNC}^{\mathrm{A}} \mathrm{C}^{-} \mathrm{3}^{\prime}$. Note that, in particular, in the first 
Table 2. APF binding sites and liver-specific genes

\section{A : APF binding sites in liver-specific genes}

\author{
ALBUMIN \\ rat \\ mouse \\ human \\ chicken \\ Xenopus $68 \mathrm{Kd}$ \\ Xenopus $74 \mathrm{Kd}$ \\ $\boldsymbol{\alpha} \cdot$ FETOPROTEIN \\ rat \\ mouse \\ human
}

$\alpha$ 1.ANTITRYPSIN

human

B.FIBRINOGEN

rat

$\alpha \cdot$.FIBRINOGEN

rat

PYRUVATE KINASE

rat

HAPTOGLOBIN

human

CONSENSUS :

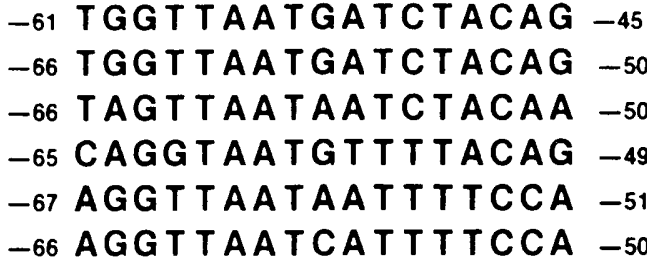

-65 AGGTTACTAGT TAACAG -49

-63 AGGTTACTAGTTAACAG -47

-60 AGGTTACTAGTTAACAG -44

-74 TGGTTAATATTCACCAG -58

-81 TAGT TAATAT T TGACAG -97

-43 AGGTTAATCATCACCCT -60

-91 TGGTTATACT TTAACCA -75

-141 CTGT TAAGAG T TGAGCT -157

$\underset{A}{G} \underset{C}{C} \frac{A}{T} T N T \frac{C}{T} N N C \frac{A}{C}$

\section{B : PE MUTANT OLIGONUCLEOTIDES}

PE 56

PE mut 1

PE mut 2

PE mut 3

PE mut 4

PE DS 12

PE DS 34

PE 56 P

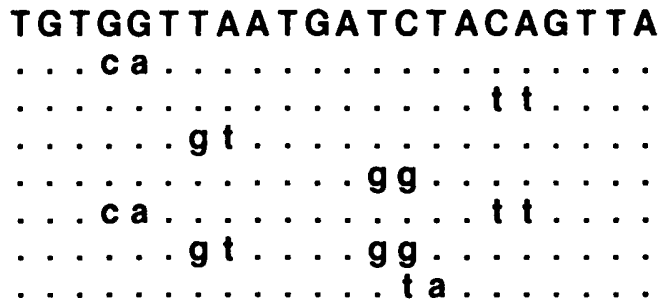

A. The APF recognition sequence of the rat albumin promoter is aligned with the homologous sequences of the Xenopus albumin genes coding for the 68-kD and 74-kD proteins (Schorpp et al. 1988); the mouse and human albumin genes (Heard et al. 1987 and references therein); the rat, mouse, and human AFP genes (Godbout et al. 1986; Chevrette et al. 1987; and references therein); the human A1AT gene (De Simone et al. 1987); the $\alpha$ - and $\beta$-fibrinogen genes (Courtois et al. 1987); the pyruvate kinase gene (Noguchi et al. 1987), and the human haptoglobin gene (Oliviero et al. 1987). B. The position and the replaced bases are indicated. Only the upper strands are shown.

part of this motif the sequence ${ }_{A} G_{\text {GTTA }}{ }_{C}$ is strongly conserved, whereas most of the sequence degeneracy occurs in the second half. As already mentioned, the APF-binding site is included in a region of partial dyad symmetry. The entire pseudopalindrome is involved in binding because $\mathrm{G}$ residues in both halves are in contact with the protein (Fig. 4). However, the contact points are not symmetrically placed with respect to the center of dyad symmetry.

To examine whether the palindromic structure per se is a crucial part of the APF recognition sequence and to study the respective roles of the different residues, we constructed a series of oligonucleotides containing double point mutations in each half of the putative dyad 
element. These altered oligonucleotides were analyzed for their ability either to compete with the wild-type probe for binding or to interact with APF and VAPF in the gel retardation assays.
These particular mutations were selected on the basis of both the A PF contact sites, derived from DMS interference mapping, and the strong conservation or certain nucleotides within the recognition sequence. Strikingly,
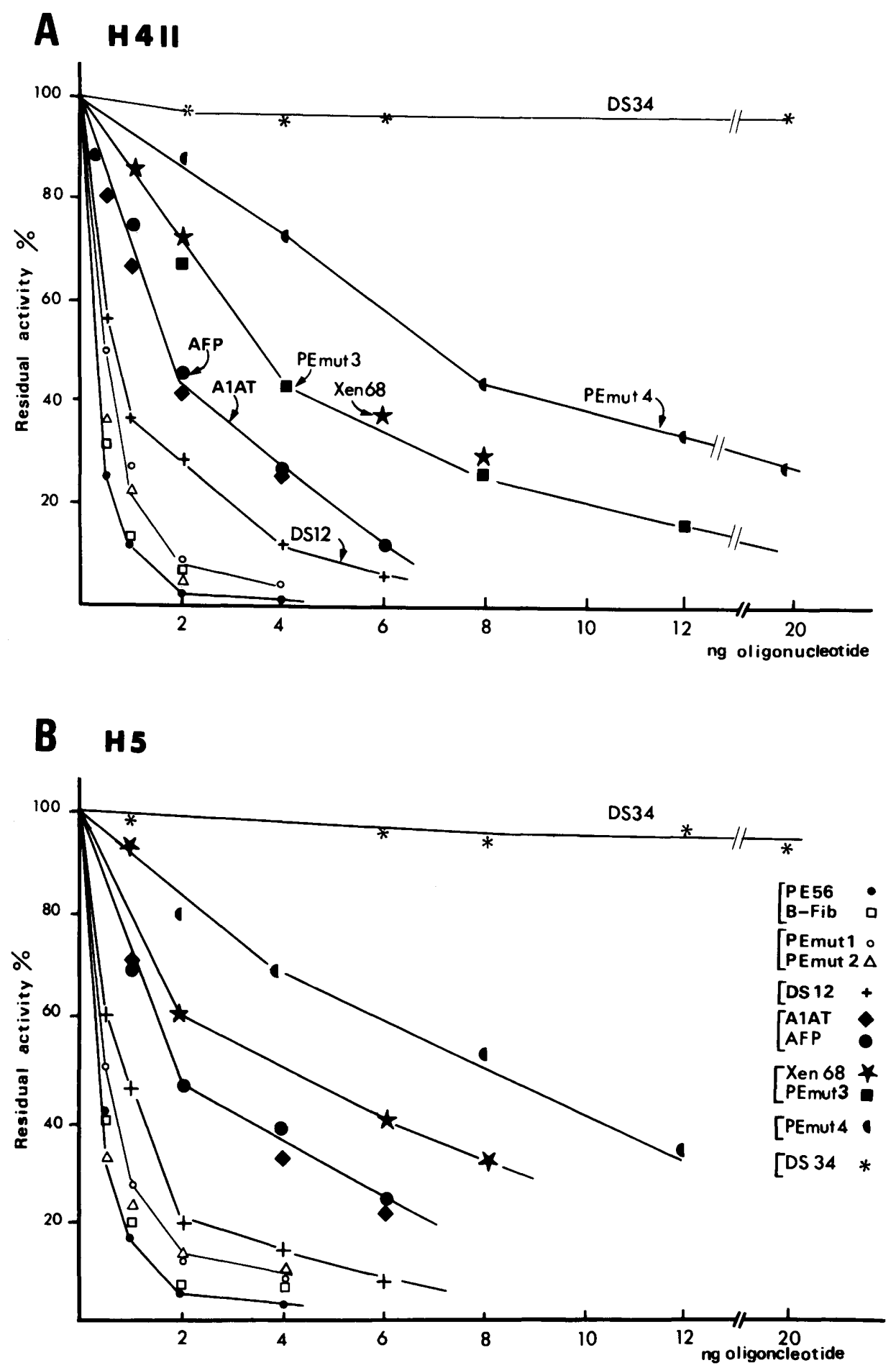

Figure 7. Relative affinities of APF and vAPF proteins for various related and mutants APF-binding motifs. Binding reactions were performed with $5 \mu \mathrm{g}$ of $\mathrm{H} 4 \mathrm{II}$ nuclear protein $(A)$ and $10 \mu \mathrm{g}$ of $\mathrm{H} 5$ nuclear protein $(B), 0.25 \mathrm{ng}$ of [ $\left.{ }^{32} \mathrm{P}\right]$ PE56 oligonucleotide, and the indicated amounts of unlabeled ds oligonucleotides. The concentration of unlabeled oligonucleotide is indicated on the abscissa; the amount of residual complex, expressed as a percentage of that found in the absence of competitor $(100 \%)$, is indicated on the ordinate. Binding activity was quantitated by densitometry of the retarded $\mathrm{C} 1$ complex (H4II, $A)$ and $\mathrm{C} 2$ complex $(\mathrm{H} 5, B)$. The sequences of the various unlabeled oligonucleotides are given in Tables 1 and 2. 
none of these double point mutants abolished the interaction with APF as revealed by bandshift assays (Fig. 7). In particular PE mut 3 and PE mut 4, in which a double transversion was introduced in positions either strongly conserved (PE mut 3) or conserved and in contact with the protein (PE mut 4), are still able to compete for APF binding.

We then analyzed the effect of introducing double point mutations on both sides of the palindrome by combining PE mut $1+$ PE mut 2 (PE DS 12) and PE mut $3+\mathrm{PE}$ mut 4 (PE DS 34), respectively. As shown in Figure 7, PE DS 12 competed less efficiently than the parental mutants for APF binding, yet it was still able to interact with the protein. PE DS 34 did not compete at all and it was the only mutant among the whole series examined (Table 2B) that totally abolished APF binding. These results indicate that either the more critical nucleotides involved in APF binding are situated in the central part of the 15-bp recognition site or that there are several alternative contacts along this sequence. Moreover, it appears that a palindromic structure is not a strict requirement for APF interaction, because APF displayed a similar affinity for the PE56 oligonucleotide, which contains an imperfect palindrome $(4 / 6)$, and for PE $56 \mathrm{P}$, which contains a perfect palindrome (GTTAATGATTAAC; Table 2B; data not shown).

The entire set of oligonucleotides listed in Tables 1 and 2 was also used to perform similar experiments with nuclear extracts from dedifferentiated variant $\mathrm{H} 5$ cells. This fine-specificity analysis again failed to reveal any significant difference in the recognition sites of APF and vAPF (Fig. 7). We are led to conclude the APF and vAPF bind indistinguishably, not only to the albumin proximal element but also to the promoter regions of Xenopus albumin, AlAT, $\beta$-fibrinogen, and AFP genes.

\section{APF functions as a positive transcription factor in vitro}

APF interacts with crucial regulatory sequences of the albumin promoter. Linker substitutions within the proximal element lead to roughly a 10 - to 30 -fold reduction in albumin-specific transcription in vivo as assayed in a transient expression system (P. Herbomel et al., in prep.). These results suggest that the interaction of APF with the proximal promoter region is actually required for efficient transcription of the gene. To establish this more directly, we used a cell-specific in vitro transcription system from rat liver that faithfully transcribes the albumin promoter (Gorski et al. 1986). To allow an easy and rapid analysis of the in vitro-synthesized transcripts we employed the assay system developed by Sawadogo and Roeder (1985a), in which the promoter is linked to artificial DNA fragments that do not contain $G$ residues on the messenger strand. In the absence of GTP the RNA polymerase can only synthesize RNA on the artificial "G-free cassette." The size of the transcripts is then defined only by the cap site and the first $G$ residue flanking the $3^{\prime}$ border of the cassette. Two G-free cassette templates were used. One, as internal control, contains the adenovirus 2 major-late promoter $1-400$ to
$+10)$ and generates a transcript 390 nucleotides long (Sawadogo and Roeder 1985). Because all our constructs containing the rat albumin promoter /the parental -400 to +16 and its $5^{\prime}$ deletions and linker scanning derivatives; see Heard et al. 1987) have G residues downstream of the cap site, we were unable to clone these promoter fragments directly in front of the cassette. For this reason, we used as specific albumin template the Alb400 construct (Gorski et al. 1986) which contains the mouse albumin promoter from positions -650 to +22 . We should point out that the 5 -flanking sequence from the mouse and rat albumin genes shows more than $90 \%$ conservation; more specifically, the sequence included in the PE56 fragment is identical in these two promoters (Heard et al. 1987). Furthermore, the same DNA-protein interactions are displayed by rat liver nuclear extracts within the -30 to -180 albumin promoter regions of these two rodent species (Cereghini et al. 1987) and the mouse and rat promoters are indistinguishable in transient transfection assays (Heard et al. 1987).

If binding of APF to its target sequence is indeed required for in vitro transcription of the albumin promoter, it might be expected that the inclusion of an excess of PE56 oligonucleotide in the in vitro reaction would inhibit its transcriptional activity, whereas mutant oligonucleotides negative for binding should not have any effect. To avoid competition for factors present in limiting amounts and to facilitate our in vitro transcriptional competition assays, we used subsaturing concentrations of the two templates $(3.5 \mu \mathrm{g} / \mathrm{ml}$ for Alb400 and $1.75 \mu \mathrm{g} / \mathrm{ml}$ for AdML390.

As illustrated in Figure 8, addition of increasing amounts of PE56 oligonucleotide progressively decreased the level of albumin specific transcription without affecting the AdML390 transcription. The inclusion of the PEDS 34 mutant, negative for binding, had no effect on transcription of either Alb400 and AdML390.

We have also compared the ability of the different PE mutants as well as $\beta$-fibrinogen, AFP and Xen 68 oligonucleotides, to compete for albumin-specific transcription. All of them are able to specifically compete Alb400 transcription, and more importantly, there is a good correlation between the binding affinities of these various oligonucleotides for APF and their effect on albumin specific transcription (Fig. 8 and results not shown). Taken together, these results indicate that APF functions as a positive transcriptional factor and its interaction with the albumin proximal element is required for efficient transcription.

\section{Discussion}

The results presented here describe the identification and characterization of two distinct factors, APF and vAPF, which bind specifically and in an indistinguishable fashion to crucial promoter sequences of the albumin and other liver-specific genes. The 5'-flanking region of the albumin gene is recognized by at least four additional distinct nuclear factors. These factors are: 


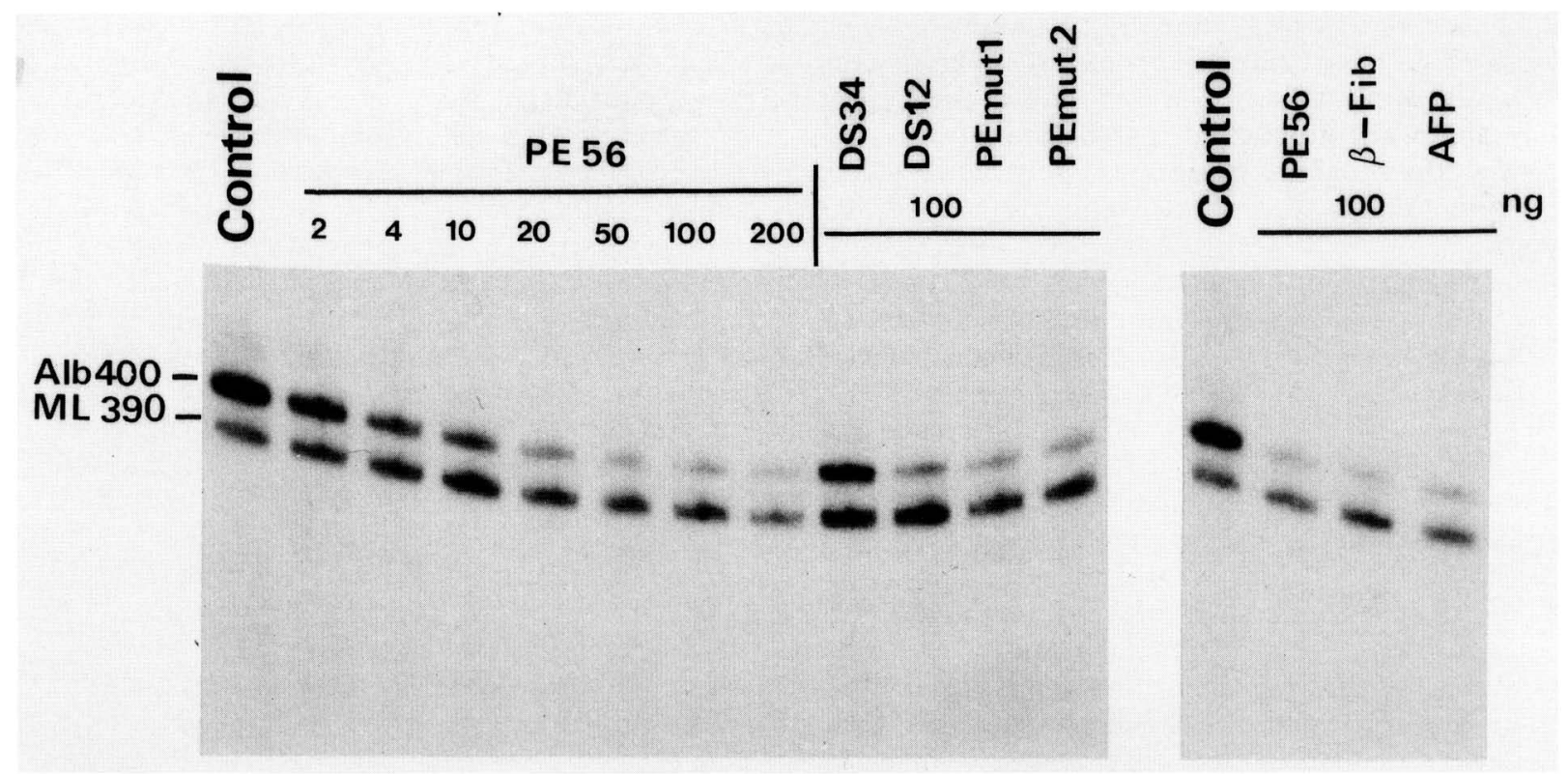

Figure 8. APF functions as a positive transcription factor in vitro. In vitro transcription assays using a rat liver nuclear extract (Gorski et al. 1986) were performed as described in Material and methods. Each reaction contained $70 \mathrm{ng}$ of Alb400 template and $35 \mathrm{ng}$ of AdML390 template, each of which generates a specific transcript of 400 and of 390 nucleotides long, respectively. The AdML390 was used as internal reference. The indicated amounts of ds oligonucleotide competitor (see Table 1) were included in the in vitro transcription reactions. The Alb400 template added correspond to $0.4 \mathrm{ng}$ of the PE56 sequence. The transcriptional signals of each template were quantitated by densitometry and the values were normalized to the internal reference. One hundred percent represents the Alb400 transcriptional signal obtained in the absence of competitor oligonucleotide. Addition of 2, 4, 10, 20,50, and 100 ng of PE oligonucleotide decreased albumin-specific transcription of $51,24,18,15,8$, and $3 \%$, respectively. The values of albumin-specific transcription obtained in the presence of $100 \mathrm{ng}$ of the other indicated oligonucleotides ranged from 3 to $12 \%$, except in the case of DS 34. Note however, that above $50 \mathrm{ng}$ ( 125 molar excess) inhibition of transcription from both templates was observed. To compare the effect on Alb400-specific transcription and the relative APF affinities for different oligonucleotides, competition analysis were also performed at lower concentrations of competitor (not shown).

ACF/NFY which recognizes the albumin CCAAT motif (Raymondjean et al. 1988), C/EBP which interacts with the DEI element (S. Cereghini and P. Johnson, unpubl.), and NF1 or a closely related protein which binds to the DEII element. Another factor not yet identified (perhaps again C/EBP) interacts with the DEIII element (Cereghini et al. 1987; Lichtsteiner et al. 1987).

The recognition sites of the first three factors encompass sequences that have been shown to be required for efficient albumin-specific transcription both in vivo (Heard et al. 1987; P. Herbomel et al. in prep.) and in vitro (Lichtsteiner et al. 1987). However, none of these factors, ACF/NFY, NF1, and C/EBP, appears to be strictly cell-type specific at least as judged both by footprint and gel retardation assays. Even though the binding activity of C/EBP varies among different cell types and is clearly more abundant in liver than in other organs (Cereghini et al. 1987; Lichtsteiner et al. 1987), similar levels were observed in cells expressing or not expressing the albumin gene (results not shown). On the contrary, the protein APF that interacts with the proximal promoter element is the only one, among the various factors binding to the albumin regulatory region, that was found to be restricted to liver/hepatoma cells producing albumin. This differential distribution may in part account for the tissue-specific activity of the albumin promoter in vivo.

\section{APF functions as a promoter-specific transcription factor}

APF binds to a sequence motif just upstream of the TATA box that serves as a functional proximal promoter element in vivo. Specifically, a linker scanning mutant, which contains multiple base substitutions within the -55 to -40 region spanning almost the entire APF binding site, causes a 10 - to 30 -fold reduction in albumin-specific transcription in vivo (P. Herbomel et al., in prep.) and, as expected, selectively abolishes APF binding to the proximal element in a footprinting assay (not shown).

The in vitro transcription experiments shown here provide further evidence that APF functions as a promoter-specific transcription factor. Thus, addition of increasing amounts of an oligonucleotide containing the APF binding site progressively and specifically inhibited 
albumin-specific transcription in vitro, whereas addition of a negative-binding mutant oligonucleotide had no effect. This implies that interaction of APF with its target sequence is required for transcriptional activation.

Unlike other well-characterized promoter-specific transcription factors, such as SP1, NF1/CTF, or MLTF/ USF, that are present in several cell types, APF exhibits a pronounced cell-type specificity. In this respect, APF is similar to the lymphoid-specific transcription factor (OTF-2) and to the pituitary-specific GHF-1 factor which are involved in the tissue-specific expression of the immunoglobulin and hormone growth genes, respectively (Staudt et al. 1986; Bodner and Karin 1987; Scheidereit et al. 1987).

The good correlation between the cell type distribution of APF-binding activity, its stimulatory activity in vitro, and the requirement of its recognition sequence for efficient albumin-specific transcription in vivo strongly suggest that APF is a primary determinant of the tissue and cell specificity of this promoter. APF and its recognition sequence however are necessary, but not sufficient, for promoter function. Deletion of the entire distal part of the promoter $(-150$ to -93$)$ which includes DEI, DEII, and DEIII elements abolishes transcriptional activity (Heard et al. 1987). Thus, it seems that the entire set of factors (NF1, C/EBP, ACF/NFY, $\mathrm{APF}$, and perhaps others) have to interact simultaneously to sustain the maximal activity of the albumin promoter.

APF may not only function as a rate-limiting factor in the initiation of albumin transcription, but may also define an active chromatin structure around the promoter, either directly or by preventing accessibility to nonspecific repressors. This in turn may allow other ubiquitous factors (NI 1, TFIID, etc.) and the RNA polymerase II to bind to the promoter and constitute the final active transcriptional complex. In cells not expressing albumin, the absence of APF and/or the presence of modified forms of APF (see below), would result in the assembly of inactive chromatin on the promoter region and the gene would be silent. The unproductive interaction of ubiquitous factors with the promoter regions of quiescent genes is then avoided; this hypothesis is compatible with the recent observation of cell-type specific interaction of ubiquitous factors with the tyrosine aminotransferase (TAT) gene in vivo (Becker et al. 1987). It is clear, however, that during development additional mechanisms are involved in establishing the strict celltype specificity of the albumin gene. In this regard, Pinkert et al. (1987) have shown that an enhancer, located $10 \mathrm{~kb}$ upstream of the mouse albumin gene, is required for liver-specific expression in transgenic mice. These remote sequences may be involved in the generation of an active chromatin configuration during development.

\section{APF binds to regulatory regions of other liver-specific genes}

The APF-binding site is characterized by a 15 -bp imperfect palindromic sequence $1-60$ GGTTAATGATC-
TACA - 46). Palindromic sequences are often targets for specific DNA-binding proteins in prokaryotes and most prokaryotic regulatory proteins recognize these sequences as dimers (Pabo and Sauer 1984).

In eukaryotes however, while some DNA-binding proteins recognize symmetrical sites [NFI, SRF, HSTF (heat shock transcription factor), MLTF/USF], others clearly bind to asymmetrical sequences (Spl, OTF-1, and OTF-2) (Borgmeyer et al. 1984; Dynan and Tjian 1985; Sawadogo and Roeder 1985b; Chodosh et al. 1986; Prywes and Roeder 1986; Shuey and Parker 1986; Treisman 1986; Fletcher et al. 1987; Scheideret et al. 1987; see references therein). DMS interference experiments show that APF contacts purine residues included in the entire pseudopalindrome, yet these residues are not symmetrically placed with respect to the putative dyad center. The fact that double point mutants that almost completely destroy the imperfect two-fold symmetry of the APF recognition site still bind APF, albeit with less affinity, suggests that the palindromic structure per se is not a crucial determinant for binding.

A sequence homologous to the APF recognition site is present at similar positions in the promoter regions of several other genes whose expression is restricted to liver cells. We show that APF not only interacts with the PE element of the rat and mouse albumin genes, but also with the homologous motif present in the Xenopus $68-\mathrm{kD}$ albumin, AFP, $\beta$-fibrinogen, and AlAT promoters. Evidence for this comes not only from the observation of identically migrating bands in the bandshift assay, but also from a series of cross-competition experiments. Thus, the relative affinities for the Xenopus $68-\mathrm{kD}, \beta$-fibrinogen, A1AT, and AFP oligonucleotides revealed by the competition assay correlate well with the binding efficiency estimated from the intensity of the DNA-protein complexes in the gel retardation assay. Moreover, the same correlation between binding affinities of these various oligonucleotides and their effect on albumin-specific transcription was observed in an in vitro transcription competition assay.

Most important, the APF-binding site present in these diverse groups of genes encompasses sequences that have been shown to be crucial for the tissue-specific expression of the respective genes (Godbout et al. 1986; Courtois et al. 1987; De Simone et al. 1987; Schorpp et al. 1988). Thus, despite the lack of obvious structural homology among liver-specific genes, it is probable that they use common elements and factors to achieve their cell-type specificity.

While this work was in progress, several groups reported the identification of liver-specific factors that bind to the promoter regions of the AlAT /the $\alpha$ ITFB protein; De Simone et al. 1987), the $\alpha$ - and $\beta$-fibrinogen (HNF-1; Courtois et al. 1987), the Xenopus albumin (HP1-binding protein; Schorpp et al. 1988), and the mouse albumin genes (B-protein; Lichsteiner et al. 1987). Because these proteins interact with the homologous APF motif present in these promoters, it is highly probable that these differently designated proteins are all the same factor or a family of related factors. However, 
because formal evidence is still lacking, we prefer to refer to the factor characterized here as APF.

\section{A different protein interacts with the albumin proximal element in dedifferentiated hepatoma cells}

Dedifferentiated hepatoma cells, such as H5 and C2, that fail to express most or all of the liver-specific functions characteristic of their line of origin, have been isolated and characterized by the group of $M$. Weiss (Deschatrette and Weiss 1974; see also Fig. 1B). In these variant cells no transcription of the albumin and other liver-specific genes can be detected (Casio et al. 1981; Clayton et al. 1985). H5 is a direct derivative of H4II and, at least morphologically, appears to diverge more strongly from the differentiated cells than $\mathrm{C} 2$ cells do. Moreover, C2 can give rise to revertants to the differentiated phenotype at a low frequency $\left(10^{-7}-10^{-8}\right)$ whereas H5 cannot (Deschatrette 1980). In both of these dedifferentiated variants as well as in a somatic hybrid (HF1) formed by fusing the differentiated Fao cells with $\mathrm{H} 5$, the APF-binding activity is not detectable. Instead the proximal element is recognized by a distinctly less abundant factor, vAPF.

The fact that VAPF is present in two independent dedifferentiated clones and in an extinguished somatic hybrid strongly suggests that this variant protein does not arise from a simple mutational event. This notion is further supported by the following observation. In C2Rev7, a revertant derived from $\mathrm{C} 2$ that expresses most of the liver-specific functions, including the synthesis and secretion of albumin (Deschatrette et al. 1980), we found only APF- and not vAPF-binding activity (Fig. 2A). Furthermore, APF and not vAPF is found in an albumin-positive segregant of HF1 somatic cell hybrids. Thus, APF is clearly associated with the hepatic phenotype and vAPF with the dedifferentiated pattern. In no case do vAPF and APF appear to coexist within the same cell.

APF and VAPF differ in their polypeptide composition and display different thermostability. Both factors, however, show similar binding specificities and therefore probably are related at least in their DNA-binding domains. The observation of two distinct factors binding indiscriminately to the same regulatory sequence raises questions regarding their functional and structural relationship. An obvious question we addressed early in our studies was whether vAPF is acting as a repressor-like molecule by direct interaction with proximal promoter sequences of the albumin and other liver-specific genes. In other words is vAPF itself an extinguishing protein? Extinction of albumin expression as well as other liver functions has been observed upon fusion of differentiated hepatoma cells with dedifferentiated variants or fibroblasts (Mevel-Ninio and Weiss 1981; Ott et al. 1984a). Moreover, the selective extinction of albumin is directly related to the presence of a single chromosome and appears to act on or via the $5^{\prime}$-flanking albumin promoter sequences (Petit et al. 1986). This phenomenon is consistent with the view that negative trans-acting factors present in nonhepatic cells prevent the action of positive factors by interfering with either their synthesis or their functional binding. Three lines of evidence argue against the hypothesis that vAPF functions directly as an extinguisher molecule. First, extinguishers are apparently specific for only one function (Petit et al. 1986) and vAPF interacts with several liver-specific genes as does APF. In particular, the hybrid clones that show selective extinction of albumin production are not blocked in the synthesis of $\beta$-fibrinogen, as would be expected if the albumin extinguisher were vAPF. Second, when $\mathrm{C} 2$ and $\mathrm{H} 5$ are fused with differentiated hepatoma cells, although both cause extinction of expression of the hepatic-specific functions of the differentiated parent, in the fusion involving $\mathrm{C} 2$, the extinction is only transitory, while that imposed by $\mathrm{H} 5$ is stable and heritable. Finally, extinction is also observed when differentiated cells are fused with fibroblasts which apparently lack vAPF.

vAPF is clearly associated with the lack of expression of liver-specific traits in dedifferentiated cells and we suggest that the appearance of this modified protein is the consequence of extinction, without being its direct cause.

Previous experiments involving footprint analysis of mixed extracts showed that the distinct pattern of DNA-protein interactions on the proximal element of dedifferentiated $\mathrm{H} 5$ extracts is dominant over that of the differentiated H4II extracts (Cereghini et al. 1987). However, no dominance was observed in the bandshift assays when extracts from H4II and $\mathrm{H} 5$ cells were mixed (Fig. 5). The reason for the discrepancy between the results obtained with these two techniques is presently unknown, but it may be due to differences in the assay conditions (in particular, a higher ratio of protein : carrier DNA in footprintings relative to gel retardation assays) which may modify the interaction of protein with DNA. Moreover, since APF and vAPF appear not to coexist in the same cell type, the in vivo relevance of the dominance we observed in the DNase I footprints remains unclear.

How are VAPF and APF related? One possibility is that these two proteins have the same primary structure but they are postranslationally modified in their non-DNAbinding domain, so that their functional specificity is altered. Alternatively, they may differ in their primary structure being encoded either by a family of genes sharing a common DNA-binding exon or from a single gene by alternative splicing.

Finally, it is likely that in cells of different histotypic origin such as fibroblasts, the albumin genes and other liver-specific genes are set aside in an inactive compact chromatin structure, so that they are not accessible to positive and negative trans-acting factors. The variant or modified factor described here may be important in the first steps of the differentiation pathway. The fact that dedifferentiation and reversion affect the entire group of hepatic functions suggests that a common mechanism regulates the expression of each of the liver-specific proteins. A tempting hypothesis is that the maintenance, loss, and acquisition of the hepatocyte differentiated state is mediated by APF and vAPF activities. 


\section{Materials and methods \\ Cell culture}

The rat hepatoma cells used (H4II, Fao, H5, C2Rev7, C2) are clonal descendants of line H4IIC3 derived from the Reuber H35 hepatoma of rat (Deschatrette and Weiss 1974; see Fig. 1B). BW1J is a subclone of the mouse hepatoma BW (Cassio and Weiss 1979).

All hepatoma cells, including the human hepatoma HepG2 cells, were cultured in modified Ham's F12 medium supplemented with $5 \%$ fetal calf serum (FCS) as described previously (Ott et al. 1984). Somatic hybrids HF-1 and HFl-5 were cultured as described by Deschatrette et al. (1979).

\section{Isolation of nuclei and preparation of nuclear extracts}

Nuclei from rat liver were prepared as described by Gorski et al. (1986), except that all buffers contained the protease inhibitors aprotinin $(1 \mu \mathrm{g} / \mathrm{ml})$, benzamidine ( $2 \mathrm{mM})$, and PMSF (0.5 mM). Nuclei from all cell lines were isolated and the respective nuclear extracts as well as the liver extracts were prepared essentially as previously described by Cereghini et al. (1987), except that all solutions contained $5 \mu \mathrm{g} / \mathrm{ml}$ of the following protease inhibitors: aprotinin, leupeptin, pepstatin, chymostatin, and antipain, in addition to $2 \mathrm{mM}$ benzamidine and $0.5 \mathrm{mM}$ PMSF. Nuclear extracts were divided into small aliquots and were frozen and stored in liquid nitrogen. Protein concentration was determined by the method of Bradford (1976).

\section{Gel retardation and DMS interference assays}

Binding reactions for bandshift assays used a $14-\mu l$ volume of reaction mix consisting of $10 \mathrm{mM}$ HEPES $(\mathrm{pH} 7.9), 30 \mathrm{mM} \mathrm{KCl}$, $10 \%$ (vol $/ \mathrm{vol}$ ) glycerol, $0.5 \mathrm{mM} \mathrm{DTT}, 5 \mu \mathrm{g} / \mathrm{ml}$ of the protease inhibitors mentioned above; $1.5 \mu \mathrm{g}$ of poly $\mathrm{dl}-\mathrm{dC} ; 1 \mu \mathrm{g}$ of sonicated salmon sperm DNA; $0.25-1$ ng of ${ }^{32} \mathrm{P}$-labeled 5 '-end dsoligonucleotide; and, unless otherwise indicated, $9 \mathrm{mM} \mathrm{MgCl}$ and $9 \mathrm{~mm}$ spermidine. Protein $(1-12 \mu \mathrm{g})$ was added to the reaction $\mathrm{mix}$ and incubation was carried out for $10 \mathrm{~min}$ on ice. DNA-protein complexes were loaded onto a low-ionicstrength, $6 \%$ acrylamide (30:1 cross-linking ratio) containing $0.25 \times$ TBE $(1 \times$ TBE : $89 \mathrm{~mm}$ Tris, $89 \mathrm{~mm}$ boric acid, $1 \mathrm{~mm}$ EDTA) and electrophoresed at $12 \mathrm{~V} / \mathrm{cm}$ until a suitable separation was achieved. The gel was then fixed, dried, and subjected to autoradiography. For DMS interference assays, the DNA probe was partially methylated with DMS as described (Maxam and Gilbert 1980) before using in a preparative scale binding reaction. After electrophoresis that wet gel was autoradiographed at $4^{\circ} \mathrm{C}$ for $4 \mathrm{hr}$, complexed, and free DNA excised from the gel, eluted, precipitated, and subjected to alkali treatment as described (Raymondjean et al. 1988). The $\mathrm{G}+\mathrm{A}$ reaction products were analyzed on a gel of $25 \%$ polyacrylamide $-7 \mathrm{M}$ urea.

For heat treatment, nuclear extracts were aliquoted into Eppendorf tubes $(25 \mu 1 /$ tube), heated at the indicated temperature, and then cooled to $0^{\circ} \mathrm{C}$. Denatured proteins were removed by centrifugation (5 min in an Eppendorf microfuge) and proteins from the supernatant were used in a standard gel retardation assay.

\section{Photoactivated DNA-protein crosslinking}

The DNA probe was generated by primed synthesis after annealing of a 10-mer primer 5'-TAACTGTAGA-3' to the upper strand of PE 27 -mer oligonucleotide $\left(5^{\prime}\right.$-TCGACTGTGGTTAATGATCTACAGTTA-3') using [ $\left.{ }^{32} \mathrm{P}\right]$ dATP $(40 \mu \mathrm{Ci}, 3000$
$\mathrm{Ci} / \mathrm{mole}$ ) and $0.1 \mathrm{mM} \mathrm{dCTP}, \mathrm{dGTP}$, and 5-bromodeoxyuridine triphosphate in a $30 \mu 1$ reaction. The probe was purified by phenol and chloroform extraction and ethanol precipitation, and used in a preparative scale binding reaction. After electrophoresis, the wet gel was irradiated with an ultraviolet light lamp (312-nm wavelength) for $10 \mathrm{~min}$ and autoradiographed for 30-60 min at $4^{\circ} \mathrm{C}$; DNA-protein complexes were excised from the gel and directly loaded on a $10 \%$ SDS-polyacrylamide gel. The contribution of a 27 -mer oligonucleotide in the protein mobility is equivalent to roughly $15 \mathrm{kD}$. A detailed description of this procedure will be reported elsewhere (S. Hirai et al., in prep.).

\section{In vitro transcription assays}

In vitro transcription assays using rat liver nuclear extracts were performed essentially as described by Gorski et al. (1986), except that each reaction contained $3.5 \mu \mathrm{g} / \mathrm{ml}$ of pAlb400 and $1.75 \mu \mathrm{g} / \mathrm{ml}$ of pML390 template DNAs and $0.9 \mathrm{mg} / \mathrm{ml}$ of protein (see Fig. 8 legend).

\section{Acknowledgments}

We are grateful to $T$. Chouard for participation in the DMS methylation interference experiments with rat liver extracts, $S$. Hirai for helpful advice in the ultraviolet DNA-protein crosslinking technique; to C. Deschatrette, M.-O. Ott, and M. Weiss for advice in culturing hepatoma cells; to $M$. Weiss for making available to us many cell lines from her collection; to B. Arcangioli for help in the synthesis of oligonucleotides and protein gels; to M. Sawadogo and U. Schibler for providing us with plasmids pML390 and pAlb400, respectively; to G. Ryffel for communicating preprints; to A. Doyen for culturing cells; to J. Ars for preparation of the manuscript; and to $M$. Weiss, P. Herbomel, and $\mathrm{R}$. Sousa for critical reading of the manuscript. Marta Blumenfeld is a fellow from the CONICET (Consejo Nacional de Investigaciones Cientificas y Tecnicas, Argentina.) This work was supported by grants from CNPS INSERM, the Foundation pour la Reserche Medicale Français, and EEC-B Biotechnology Action Programme.

\section{Note added in proof}

Kugler et al. (Nucleic Acids Res. 16: 3165, 1988) show that the APF homologous motifs present in the Xenopus albumin (HP1), $\beta$-fibrinogen, $\alpha 1$-antitrypsin and albumin genes bind an identical factor and are able to confer increased transcription in nuclear extracts from rat liver.

\section{References}

Babiss, L.E., R.S. Herbst, A.L. Benett, and J.E. Darnell. 1987. Factors that interact with the rat albumin promoter are present both in hepatocytes and other cell types. Genes Dev. 1: 256-267.

Becker, P.B., S. Ruppert, and G. Schütz. 1987. Genomic footprinting reveals cell type-specific DNA binding of ubiquitous factors. Cell 51: 435-448.

Borgmeyer, U., J. Nowock, and A.E. Sippel. 1984. The TGGCAbinding protein: a eukaryotic nuclear protein recognizing a symmetrical sequence on double-stranded linear DNA. Nucleic Acids Res. 12: 4295-4311.

Bodner, M. and M. Karin. 1987. A pituitary-specific trans-acting factor can stimulate transcription from the growth hormone promoter in extracts of nonexpressing cells. Cell 50: 267270. 
Bradford, M.M. 1976. A rapid and sensitive method for the quantitation of microgram quantities of protein utilizing the principle of protein dye binding. Anal. Biochem. 72: 248254.

Briggs, M.R., J.T. Kadonaga, S.P. Bell, and R. Tjian. 1986. Purification and biochemical characterization of the promoterspecific transcription factor Spl. Science 243: 47-52.

Cassio, D. and M.C. Weiss. 1979. Expression of fetal and neonatal hepatic functions by mouse hepatoma rat hepatoma hybrids. Somatic Cell Genetics 5: 719-738.

Cassio, D., M.C. Weiss, M.-O. Ott, J.M. Salat-Trepat, and T. Erdos. 1981. Expression of the albumin gene in rat hepatoma cells and their dedifferentiated variants. Cell 27: 351-358.

Cereghini, S., M. Raymondjean, A. Garcia-Carrança, P. Herbomel, and M. Yaniv. 1987. Factors involved in control of tissue-specific expression of albumin gene. Cell 50: 627-638.

Clayton, D., M.C. Weiss, and J.E. Darnell. 1985. Liver specific RNA metabolism in hepatoma cells: variations in transcription rates and in RNA cells. Mol. Cell. Biol. 5: 2633-2641.

Courtois, G., J.G. Morgan, L.A. Campbell, G. Fourel, and G.R. Crabtree. 1987. Interaction of a liver-specific nuclear factor with the fibrinogen and alpha-1-antrypsin promoters. Science 238: 688-692.

Chevrette, M., M. Guertin, B. Turcotte, and L. Bélanger. 1987. The rat alpha-fetoprotein gene: characterization of the $5^{\prime}$ flanking region and tandem organization with the albumin gene. Nucleic Acids Res. 15: 1338-1339.

Chodosh, L.A., R.W. Carthew, and P. Sharp. 1986. A single polypeptide possesses the binding and transcription activities of the adenovirus major late transcription factor. Mol. Cell. Biol. 6: 4723-4733.

Deschatrette, M. and M.C. Weiss. 1974. Characterization of differentiated and dedifferentiated clones from a rat hepatoma. Biochimie 56: 1603-1611.

Deschatrette, J., E.M. Moore, M. Dubois, D. Cassio, and M.C. Weiss. 1979. Dedifferentiated variants of a rat hepatoma: analysis by cell hybridization. Somatic Cell Genet. 5: 697718.

Deschatrette, J., E.M. Moore, M. Dubois, and M.C. Weiss. 1980. Dedifferentiated variants of a rat hepatoma: reversion analysis. Cell 19: 1043-1051.

Deschatrette, J. 1980. Dedifferentiated variants of a rat hepatoma: partial reversion induced by cell aggregation. Cell 19: $501-511$.

De Simone, V., G. Ciliberto, E. Hardon, G. Paonessa, F. Palla, L. Lundberg, and R. Cortese. 1987. Cis- and trans-acting elements responsible for cell-specific expression of the human alpha-1-antitrypsin gene. EMBO J. 6: 2759-2766.

Dorn, A., J. Bollekens, A. Staub, C. Benoist, and D. Mathis. 1987. A multiplicity of CCAAT box-binding proteins. Cell 50: $863-872$.

Dynan, W.S., and R. Tjian. 1985. Control of eukaryotic messenger RNA synthesis by sequence-specific DNA-binding proteins. Nature 310: 774-778.

Engelke, D.R., S.Y. Ng, B.S. Shastry, and R. G. Roeder. 1980. Specific interaction of a purified transcription factor with an internal control region of 5SRNA genes. Cell 19: 717.

Fletcher, C., N. Heintz, and R. Roeder. 1987. Purification and characterization of OTF-1, a transcription factor regulating cell cycle expression of a human histone $\mathrm{H} 2 \mathrm{~b}$ gene. Cell 51: $773-781$.

Fried, M. and D.M. Crothers. 1981. Equilibria and kinetics of lac repressor-operator interactions by polyacrylamide gel electrophoresis. Nucleic Acids Res. 9: 6506-6525.

Garner, M.M and A. Revzin. 1981. A gel electrophoresis method for quantifying the binding of proteins to specific DNA regions: applications to components of the Escherichia coli lactose operon regulatory system. Nucleic Acids Res. 9: 3047-3060.

Godbout, R., R. Ingram, and S.M. Tilghman. 1986. Multiple regulatory elements in the intergenic region between the alpha-fetoprotein and albumin genes. Mol. Cell. Biol. 6: $477-487$.

Gorski, K., M. Carneiro, and U. Schibler. 1986. Tissue specific in vitro transcription from the mouse albumin promoter. Cell 47: 767-776.

Graves, B.J., P.F. Johnson, and S.L. McKnight. 1986. Homologous recognition of a promoter domain common to the MSV LTR and the HSV tk gene. Cell 44: 565-576.

Heard, J.M., P. Herbomel, M.O. Ott, A. Mottura-Rollier, M. Weiss, and M. Yaniv. 1987. Determinants of rat albumin promoter tissue specificity analyzed by an improved transient expression system. Mol. Cell. Biol. 7: 2425-2434.

Johnson, P., W.H. Landschulz, B. Groves, and S. McKnight. 1987. Identification of a rat liver nuclear protein that binds to the enhancer core of three animal viruses. Genes Dev. 1: $133-146$.

Jones, K.A., K.R. Yamamoto, and R. Tjian. 1985. Two distinct transcription factors bind to the HSV thymidine kinase promoter in vitro. Cell 42: 559-572.

Jones, K.A., J.T. Kadonaga, P.J. Rosenfeld, T.J. Kelly, and R. Tjian. 1987. A cellular DNA-binding protein that activates eukaryotic transcription and DNA replication. Cell 48: 7989.

Lichtsteiner, S., J. Wuarin, and U. Schibler. 1987. The interplay of DNA-binding proteins on the promoter of the mouse albumin gene. Cell 51: 963-973.

Maxam, A.M. and W. Gilbert. 1980. Sequencing end-labeled DNA with base specific chemical cleavages. Meth. Enzymol. 65: 499-540.

Mevel-Ninio, M. and M. Weiss. 1981. Immunofluorescence analysis of the time-course of extinction, reexpression, and activation of albumin production in rat hepatoma-mouse fibroblast heterokatyons and hybrids. J. Cell. Biol. 90: 339350 .

Noguchi, T., K. Yamada, H. Inoue, T. Matsuda, and T. Tanka. 1987. The $L$ and $R$ type isozymes of rat pyruvate kinase are produced from a single gene by use of different promoters. $J$. Biol. Chem. 262: 14366-14371.

Oliviero, S., G. Morrone, and R. Cortese. 1987. The human haptoglobin gene: transcriptional regulation during development and acute phase induction. EMBO J. 6: 1905-1912.

Ott, M.O., L. Sperling, P. Herbomel, M. Yaniv, and M. Weiss. 1984a. Tissue specific expression is conferred by a sequence from the 5' end of the rat albumin gene. EMBO /. 3: 25052510.

Ott, M.O., L. Sperling, and M. Weiss. 1984b. Albumin extinction without methylation of its gene. Proc. Natl. Acad. Sci. 81: $1738-1741$.

Pabo, C.O. and R.T. Sauer. 1984. Protein-DNA recognition. Ann. Rev. Biochem. 53: 293-321.

Panduro, A., F. Shalaby, and D.A. Shafritz. 1987. Changing patterns of transcriptional and post-transcriptional control of liver-specific gene expression during rat development. Genes Dev. 1: 1172-1182.

Petit, C., J. Levilliers, M.-O. Ott, and M.C. Weiss. 1986. Tissue specific expression of the rat albumin gene: genetic control of its extinction in microcell hybrids. Proc. Natl. Acad. Sci. 83: $2561-2565$.

Pinkert, C.A., D.M. Ornitz, R.L. Brinster, and R.D. Palmiter. 1987. An albumin enhancer located $10 \mathrm{~kb}$ upstream func- 


\section{Cereghini et al.}

tions along with its promoter to direct efficient, liver-specific expression in transgenic mice. Genes Dev. 1: 268-276.

Prywes, R. and R.G. Roeder. 1986. Inducible binding of a factor to the c-fos enhancer. Cell 47: 777-784.

Raymondjean, M., S. Cereghini, and M. Yaniv. 1988. Several CCAAT binding proteins coexist in eukaryotic cells. Proc. Nat1. Acad. Sci. 85: 757-784.

Sawadogo, M. and R. Roeder. 1985a. Factors involved in specific transcription by human RNA polymerase II: analysis by a rapid and quantitative in vitro assay. Proc. Natl. Acad. Sci. 82: $4394-4398$.

1985b. Interaction of gene-specific transcription factor with the adenovirus major late promoter upstream of the TATA box region. Cell 43: 165-175.

Scheidereit, C., A. Heguy, and R. Roeder. 1987. Identification and purification of a human lymphoid-specific octamerbinding protein (OTF-2) that activates transcription of an immunoglobulin promoter in vitro. Cell 51: 783-795.

Schorpp, M., W. Kugler, U. Wagner, and G.U. Ryffel. 1988. The hepatocyte-specific promoter element HPl of the Xenopus albumin gene interacts with transcriptional factors of mammalian hepatocytes. J. Mol. Biol. (in press).

Shuey, D.J. and C.S. Parker. 1986. Binding of the Drosophila Heat-shock gene transcription factor to the hsp 70 promoter. J. Biol. Chem. 261: 7934-7940.

Staudt, L.M., H. Singh, R. Sen, T. Wirth, P.A. Sharp, and D. Baltimore. 1986. A lymphoid specific protein binding to the octamer motif of immunoglobulin genes. Nature 323: 640643.

Treisman, T. 1986. Identification of a protein-binding site that mediates transcriptional response of the c-fos gene to serum factors. Cell 46: 567-574

1987. Identification and purification of a polypeptide that binds to the c-fos serum response element. EMBO $J$. 6: $2711-2717$. 


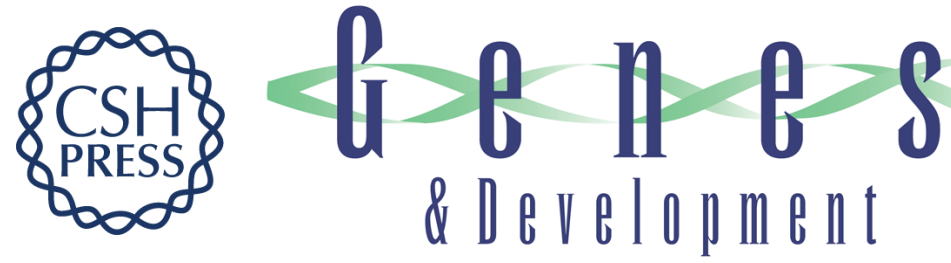

\section{A liver-specific factor essential for albumin transcription differs between differentiated and dedifferentiated rat hepatoma cells.}

$S$ Cereghini, M Blumenfeld and M Yaniv

Genes Dev. 1988, 2:

Access the most recent version at doi:10.1101/gad.2.8.957

References This article cites 51 articles, 16 of which can be accessed free at:

http://genesdev.cshlp.org/content/2/8/957.full.html\#ref-list-1

License

Email Alerting

Service

Receive free email alerts when new articles cite this article - sign up in the box at the top right corner of the article or click here.

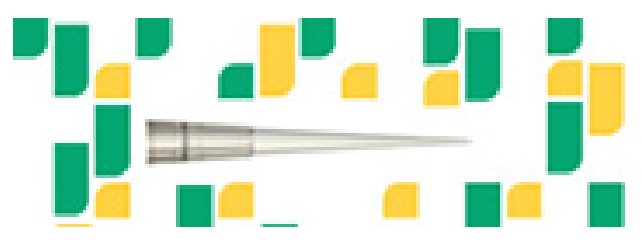

Focused on your science. 